Article

\title{
A Green Transportation Planning Approach for Coal Heavy-Haul Railway System by Simultaneously Optimizing Energy Consumption and Capacity Utilization
}

\author{
Jianjun Fu and Junhua Chen *
}

Citation: Fu, J.; Chen, J. A Green Transportation Planning Approach for Coal Heavy-Haul Railway System by Simultaneously Optimizing Energy Consumption and Capacity Utilization. Sustainability 2021, 13, 4173. https://doi.org/10.3390/ su13084173

Academic Editor: Tomio Miwa

Received: 27 February 2021

Accepted: 6 April 2021

Published: 8 April 2021

Publisher's Note: MDPI stays neutral with regard to jurisdictional claims in published maps and institutional affiliations.

Copyright: (c) 2021 by the authors. Licensee MDPI, Basel, Switzerland. This article is an open access article distributed under the terms and conditions of the Creative Commons Attribution (CC BY) license (https:// creativecommons.org/licenses/by/ $4.0 /)$.
School of Traffic and Transportation, Beijing Jiaotong University, No.3 Shang Yuan Cun, Hai Dian District, Beijing 100044, China; 12114229@bjtu.edu.cn

* Correspondence: cjh@bjtu.edu.cn; Tel.: +86-134-2602-5309

\begin{abstract}
Coal heavy-haul railway has been aiming at maximizing capacity utilization, but ignoring energy consumption for a long time. With the focus on green production, heavy-haul railways need transportation organization plans that can balance energy consumption and capacity utilization. Based on this, this paper proposes a data mining + optimization framework that uses train trajectory data to estimate train energy consumption and then uses a mixed integer programming model to simultaneously optimize plans from energy and capacity aspects. We use Gaussian distribution to describe features of energy consumption under different situations, and build a multi-dimensional cube to store these features to connect with the optimization model. In addition, a branch-andbound algorithm is design to solve the optimization model. From the sensitivity analyses we can conclude that (1) shortening the departure interval from 13 min to 9 min will generate more energy consumption, about 3.6\%; (2) combining short-form trains (50 units) with long-form trains (100 units) while increasing the carrying capacity will generate more energy consumption, about 5 14\%; and (3) by controlling weights of the optimization model, capacity-energy-balanced plans can be obtained. The results can contribute to improving the sustainability of railways.
\end{abstract}

Keywords: coal heavy-haul railway; railway train trajectory data; energy consumption; capacity utilization; simultaneously optimizing

\section{Introduction}

\subsection{Research Background}

In the coal transportation system, heavy-haul railways have been the backbone because of their high capacity for a long time. In general, maximizing the utilization of the capacity of heavy-haul railway is the main objective of operations. The most common way to achieve this objective is by a pattern that combines two short-form trains (50 units) into one long form train (100 units). However, in daily operation, it is found that although the combination can effectively increase traffic density (which leads to a high ratio of capacity utilization), it also generates more energy consumption. With the focus on green production, it is inadvisable for meeting the capacity utilization or the optimal use of energy consumption unilaterally. Heavy-haul railways are in urgent need of transportation organization solutions that can balance energy consumption and capacity utilization.

However, there are challenges in describing distributions of energy consumption of heavy-haul systems in different dimensions and in depicting the relationship between energy consumption and capacity utilization, and thus in participating in the capacity utilization planning process:

1. Although a series of automatic management and control platforms has been deployed in the railway system, the existing research still lacks ways of using these data. It is difficult to depict and analyze the distribution of train energy consumption under conditions of varying directions, time periods, and origin and destination, etc. 
2. The relationship between energy consumption and capacity utilization is difficult to determine, and there is a lack of transportation organization programming techniques that take both into account.

Motivated by these two problems, this paper proposes a data mining + optimization framework that uses train trajectory data (TTD) to estimate train energy consumption and then uses a mixed integer programming model to simultaneously optimize plans from energy and capacity aspects. We use Gaussian distribution to describe features of energy consumption under varying situations, and build a multi-dimensional cube to store these features to connect with the optimization model. In addition, a branch-and-bound algorithm is designed to solve the optimization model.

\subsection{Research Overview}

Developing models for assessing the energy consumption of rail freight has received significant attention since the 1970s [1-3]. Nowadays, many energy-oriented models are devoted to assessing the energy consumption/air pollution of rail transportation $[4,5]$. The energy models for freight transportation can be categorized into three types. The first type of model is analytical models, which can be used to estimate emissions of trains based on some assumed stochastic processes [6,7]. The second type of model is based on optimization models $[8,9])$. These models typically can model the microscopic movement of trains, which is critical for estimating accurate fuel consumption and emissions [10]. Energy-efficient rail train control and management decisions can also be incorporated into the models to analyze the environmental impact of railway movement [11-13]. The method to estimate the emissions differs by agency or rail class. The third group of models includes simulation-based approaches [14-16]. For example, the train energy model (TEM) that is widely used in the railway community is an effective tool to estimate the energy consumption of trains [17].

When the demand for transportation was greater than the supply, how to maximize the theoretical capacity of the line was the focus of research, and relatively little research was done on energy consumption. Under the new situation of energy conservation and low-carbon environmental protection, countries around the world are paying increasing attention to the construction and development of railways, further highlighting the energysaving advantages of railways. Although railway transportation provides strong protection for economic development, its energy consumption problem has also become the focus of attention and research among all countries. The existing studies have shown that factors such as the hours a train runs in a network and the headway time affect the energy consumption of the train [18]. In the past, scholars' research on railway energy consumption was mainly focused on energy consumption calculation, train operation, and control models and algorithms, and there are few studies that correlate the operation diagram with railway energy consumption. Representative works of the abovementioned studies on railway capacity, preparation of transport organization, and energy consumption of trains are shown in Table 1.

Table 1. Representative literature on the study of railway capacity, preparation of transportation organization, and energy consumption of trains.

\begin{tabular}{|c|c|c|}
\hline Scholar & Research Method & Major Contributions \\
\hline $\begin{array}{l}\text { Cucala [19] } \\
\text { Maria [20] }\end{array}$ & $\begin{array}{l}\text { Energy optimization schedule, } \\
\text { energy-efficient driving strategies }\end{array}$ & Integrated optimization of train schedules and driver behavior \\
\hline Xiang L. [21] & Driver behavior analysis & Dynamic train control and driving solution optimization \\
\hline Dingjun Chen [22] & Bi-objective evolutionary algorithm & $\begin{array}{l}\text { Establishing an energy-efficient operation diagram for } \\
\text { high-speed railways based on stop and dispatch optimization }\end{array}$ \\
\hline
\end{tabular}


Table 1. Cont.

\begin{tabular}{|c|c|c|}
\hline Scholar & Research Method & Major Contributions \\
\hline Huiru Zhang [23] & Simulated annealing algorithm & $\begin{array}{l}\text { Development of a two-layer planning model for timetable } \\
\text { optimization of high-speed rail based on energy-efficient } \\
\text { train control }\end{array}$ \\
\hline Xin Yang [24] & Train operation optimization strategy & $\begin{array}{l}\text { Building a comprehensive subway schedule and speed profile } \\
\text { optimization model }\end{array}$ \\
\hline $\begin{array}{l}\text { Bocharnikov Y. V. } \\
\text { [25] }\end{array}$ & & $\begin{array}{l}\text { Trade-off between reduced energy consumption and increased } \\
\text { running time to optimize traction energy consumption during a } \\
\text { single train run }\end{array}$ \\
\hline Bai Yun [26] & Train motion analysis and simulation & $\begin{array}{c}\text { Energy consumption at different inertial distances before } \\
\text { braking and at lower speed limits, as well as uniformity of } \\
\text { train speed }\end{array}$ \\
\hline Xiang X. [27] & Bi-level algorithm & $\begin{array}{c}\text { Selecting the optimal solution set with the lowest total cost } \\
\text { under various constraints }\end{array}$ \\
\hline Dorfman [28] & Scheduling management strategy & $\begin{array}{l}\text { For single-track train control issues } \\
\text { Using discrete event dynamic systems theory }\end{array}$ \\
\hline Albrecht [29] & A new approach to integration & Balancing simultaneity and energy efficiency in train schedules \\
\hline Ghoseiri [30] & Multi-objective train optimization mode & $\begin{array}{c}\text { Train control that takes into account both train energy } \\
\text { consumption and customer travel time }\end{array}$ \\
\hline $\operatorname{Li}[21]$ & Multi-objective train scheduling model & $\begin{array}{l}\text { Integrating goals for energy efficiency, emissions reduction, and } \\
\text { travel time }\end{array}$ \\
\hline Sicre [31] & $\begin{array}{l}\text { Simulation model to optimize energy } \\
\text { consumption }\end{array}$ & $\begin{array}{l}30 \% \text { energy saving by using existing simulation platform to } \\
\text { optimize train schedules }\end{array}$ \\
\hline Lancien [32] & Data mining and optimization model & $\begin{array}{c}\text { Aiming to minimize energy consumption of trains under fixed } \\
\text { service time conditions }\end{array}$ \\
\hline
\end{tabular}

The above studies have played roles in the organization of heavy-haul railway transportation, but there are still some gaps, mainly in the capacity-energy relationship: (1) These studies are generally based on microscopic plans before operation, with little research on energy consumption under actual operating conditions. The models they are based on consider the ideal horizontal and vertical slope, with the calculated energy consumption being the reference value prior to operation. The actual energy consumption of the heavyhaul system is poorly depicted and the estimated value differs greatly from the reality. (2) There is a lack of multidimensional energy consumption models that can be used for transportation organization optimization. There is an inability to accurately portray the impact of different dimensions such as OD (volume from Origin to Destination), running time, and load on energy consumption. (3) There is a lack of models for the simultaneous optimization of capacity and energy consumption.

\subsection{Main Article Contributions}

In order to fill the gaps, in this paper we propose a framework with data analysis methods for estimating the distribution of energy consumption in different dimensions and a mixed integer programming model is used to obtain solutions that can balance capacity and energy consumption. The contributions can be summarized as follows:

1. According to methods based on kinematic theory, an energy consumption calculation approach based on TTD is proposed, then the multidimensional energy consumption values are obtained, which include dimensions such as train forms and routes, etc. In order to solve the problem that the discrete energy consumption value cannot support the requirement of continuity of the objective function in the optimization model, we adopt Gaussian distributions under different dimensions as regression models to fit discrete energy consumption points and construct a distribution model with dimensions for the capacity- and energy-balanced optimization model.

2. A simultaneous optimization model for timetable scheduling is proposed, considering objectives including capacity and energy consumption and constraints such as section carrying capacity, station loading and unloading capacity, and station recombination 
capacity, as well as the different energy consumption characteristics of different train paths. The model is based on a time-space network and the granularity on time can be brought down to $5 \mathrm{~min}$. According to the energy consumption multi-dimensional distribution model, edge weights of the network are set. By means of finding and resolving conflicts in the timetable, we propose a branch-and-bound algorithm to solve the model.

3. By comparing and analyzing experiments, some quantitative and qualitative patterns were discovered. This can guide future plan scheduling.

The remainder of this paper is organized as follows: In Section 2, we introduce the principles and methods of energy consumption calculation, and a multi-dimensional consumption cube is built in this section. Based on the cube, in Section 3, a mixed integer programming model to simultaneously optimize plans from energy and capacity aspects is illustrated. In Section 4, we make some cases to compare energy consumptions and energy utilizations in varying conditions and discuss the reasons. Section 5 gives conclusions about the research.

\section{Framework and Methods for Energy Consumption Estimation}

Traction phases are the basic conditions during train operation and include acceleration (TA), coasting (CO), and braking (TB). Different traction phases have different energy consumptions. For this reason, the methods studied in this section start with the detection of traction phases and then we design the energy consumption calculation methods on the basis of the traction phases. To ensure the validity of the calculation results, some data management and noise cleaning methods are designed in the procedure of calculating energy consumption. The designed calculation procedure includes:

(1) TTD series data formation. This includes data pre-processing and formatting to time series data.

(2) State-based traction phase detection. This is combined with the transformation method of traction phase identification; the discrete data points in TTD data are transformed into continuous sequence segments.

(3) Noise cleaning of the TTD data for each traction phase. Correction of the data in each traction phase is completed using the Kalman filter.

(4) Energy consumption measurement method based on traction phases. Individual methods for calculating the energy consumption of trains under traction phases are designed.

(5) Multi-dimensional distribution model of energy consumption based on Gaussian distribution. This is based on the assumption of Gaussian distribution. The energy consumption distribution pattern is analyzed and the energy consumption model is established.

The flow of the energy consumption estimation is shown in Figure 1.

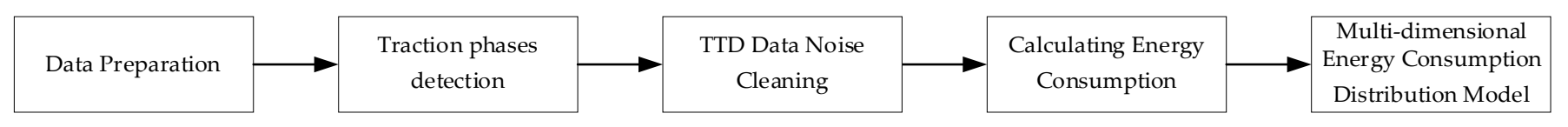

Figure 1. Logical framework for calculating energy consumption standards based on data mining.

\subsection{Data Preparation}

This section provides a data structure for the corresponding data in order to standardize the description of the formulae in the model and algorithm later on. The notations involved are shown in Table 2. 
Table 2. Definitions.

\begin{tabular}{|c|c|}
\hline Notation & Descriptions \\
\hline$D A L_{0}$ & Original format TTD (train trajectory data) data \\
\hline$t_{i}$ & The-th moment \\
\hline$p_{i}$ & Train position at time i-th \\
\hline$v_{i}$ & Train speed at time i-th \\
\hline$g k_{i}$ & Locomotive display at time i-th \\
\hline$H_{0}$ & Raw elevation data (spatially sequential) \\
\hline $\mathrm{Cur}_{\mathrm{O}}$ & Raw curve radius data (spatially sequential) \\
\hline$H_{V I}$ & Level cross-sectional data (time series) \\
\hline$h v i_{i}$ & Data points of the longitudinal and cross sections at moment $i$ \\
\hline$p^{s}$ & Kilometer marker at the end of the train's operating segment \\
\hline $\mathrm{h}_{i}$ & The elevation at which the train is located at the moment of $i$ \\
\hline Cur $_{i}$ & The radius of the curve where the train is located at moment $i$ \\
\hline$k$ & Kind of phase \\
\hline$w_{0}$ & Basic resistance of heavy vehicle units \\
\hline$w_{0}^{\prime}$ & Basic resistance of locomotive units \\
\hline$w_{r}$ & Curve unit basic resistance $\left(\mathrm{N} / \mathrm{KN}^{*}\right.$ degree $)$ \\
\hline cur $^{m}$ & curvature \\
\hline$U$ & Supply voltage \\
\hline$I_{0}$ & Self-contained electric current \\
\hline$\eta$ & Motor conversion efficiency \\
\hline$M$ & Gross train weight \\
\hline$M_{0}$ & Locomotive quality \\
\hline$\Delta h$ & The amount of elevation change before and after a traction phase sequence \\
\hline$v_{S}$ & Instantaneous velocity before a traction phase sequence \\
\hline$v_{e}$ & Instantaneous velocity after a traction phase sequence \\
\hline$l_{s}$ & Mileage position at the start of a traction phase sequence \\
\hline$l_{e}$ & End-mile position of a traction phase sequence \\
\hline$x_{\mathrm{ec}}$ & Information on train operation under different phases \\
\hline$x_{O}$ & Train departure stations \\
\hline$x_{D}$ & Train terminal \\
\hline$t_{O}$ & Train departure time \\
\hline$t_{D}$ & Final train arrival time \\
\hline wei & Train traction constant \\
\hline st & Different train stop schemes \\
\hline$v_{r}$ & Train running speed \\
\hline$E_{x_{\mathrm{ec}}}$ & Energy consumption data for specific train operations under defined conditions \\
\hline
\end{tabular}

This part uses data that include TTD data and line longitudinal and cross-sectional data. The TTD data contain detailed records of the number of trains, locomotive type, routing, grouping information, load information, kilometer sign, distance to the station ahead, ground signals, train operation speed, operation status, and other data during the operation of the train. The line longitudinal and cross-sectional data record parameters such as elevation differences, spatial position, and curve radius. The integration of the two can support the measurement of energy consumption.

The original TTD data contain various pieces of information during the train operation. We need to extract effective data reflecting the train speed, distance, time, and operation conditions. Data pre-processing is also carried out on the longitudinal and cross-sectional data to form a time series with the TTD series data in order to complete the data structure design.

TTD data are time series data, which can be expressed as

$$
\begin{aligned}
\mathrm{DAL}_{\mathrm{o}} & =\left\{\mathrm{dal}_{1}, \mathrm{dal}_{2}, d a l_{2} \cdots, d a l_{n}\right\} \\
\mathrm{dal}_{i} & =\left\{t_{i}, p_{i}, v_{i}, g k_{i},\right\}, i \in[1, n]
\end{aligned}
$$


where $\mathrm{DAL}_{\mathrm{o}}$ is the TTD data set, $d a l_{i}$ is the corresponding $i$ th data point. $n$ is the number of data points, $t_{i}$ is the time and minute at time $i, p_{i}$ is the train position at time $i, v_{i}$ is the train speed at time $i$, and $g k_{i}$ is the train status at time $i$.

The longitudinal and cross-sectional data are in the form of spatial sequences. The elevation $\mathrm{H}_{\mathrm{o}}$ and the curve radius $\mathrm{Cur}_{\mathrm{O}}$ can be expressed respectively as follows:

$$
\begin{gathered}
\mathrm{H}_{\mathrm{o}}=\left\{h_{o 1}, h_{o 2}, h_{03} \cdots, h_{o m}\right\}, j \in[1, m], p_{j} \in\left[0, p_{s}\right] \\
\text { Cur }_{\mathrm{o}}=\left\{\text { Cur_o }, \text { Cur_o }, \text { Cur_o } \cdots, C u r \_o_{n}\right\}, k \in[1, n], p_{k} \in\left[0, p^{s}\right]
\end{gathered}
$$

where $p_{j}$ and $p_{k}$ are spatial positions, $m$ is the number of segments of elevation difference, $n$ is the number of segments of curve radius, $p^{s}$ is the kilometer sign at the end position of the train operation section, $\mathrm{H}_{o}$ is the original elevation data, and $\mathrm{Cur}_{o}$ is the original curve radius data. In order to fuse with the TTD data of time series, the longitudinal and cross-sectional data were discretized into time series from moment 1 to moment $t$ as follows:

$$
\begin{gathered}
H_{V I}=\left\{h v i_{1}, h v i_{2}, \cdots, h v i_{i}, \cdots, h v i_{t}\right\} \\
h v i_{i}=\left\{h_{i}, C u r_{i}\right\}, i \in[1, t]
\end{gathered}
$$

where $H_{V I}$ is the longitudinal and cross-sectional data and $h v i_{i}$ is the longitudinal and cross-sectional data point at $i$.

Through the above steps, the $\mathrm{DAL}_{o}$ sequence, which records the train operation status, and the $H_{V I}$ sequence, which records the line change condition, can be obtained. In the subsequent steps, the $\mathrm{DAL}_{o}$ will be detected for the traction phases and the energy consumption will be calculated according to the detected phases segment.

\subsection{Traction Phase Detection}

The processed TTD data contain a large amount of discrete and fragmented train state information, such as adding front traction, unloading traction, unloading front traction, unloading rear traction, etc. These states can be divided into acceleration, coasting, and braking to facilitate the calculation of energy consumption. In this part, the train state is detected one by one according to the time sequence, and the data of the same state is divided into the same phase segment. The discrete original data is aggregated to extract the traction phase sequence, which can be used for the subsequent energy consumption calculation algorithm to calculate the energy consumption.

\subsubsection{Traction Phases Definition}

From the whole process of train operation, the operating curve of the heavy train in the coal lanes mainly consists of three parts: acceleration (TA), coasting (CO), and braking (TB). By identifying the state of discrete TTD data during train operation, it can be aggregated into continuous segments of traction service.

With train $t r$, the discrete data points during its operation can be expressed as:

$$
\begin{gathered}
\mathrm{DAL}_{\mathrm{o}}^{t r}=\left\{d a l_{1}^{t r}, d a l_{2}^{t r}, \cdots, d a l_{i}^{t r}, \cdots, d a l_{c_{t r}}^{t r}\right\} \\
d a l_{i}^{t r}=\left\{t_{i}^{t r}, p_{i}^{t r}, v_{i}^{t r}, g k_{i}^{t r}\right\}, i \in\left[1, c_{t r}\right]
\end{gathered}
$$

where DAL $\mathrm{L}_{\mathrm{o}}^{\text {tr }}$ is the TTD data set of train $t r$, dal $l_{i}^{t r}$ is the corresponding $i$ th TTD data point, $c_{t r}$ is the number of data points during train operation, $t_{i}^{t r}$ is the hour and minute at time $i$, $p_{i}^{t r}$ is the train position at time $i, v_{i}^{t r}$ is the train speed at time $I$, and $g k_{i}^{t r}$ is the train status at time $i$.

By detecting $g k_{i}^{t r}$ continuity, traction phases can be obtained, which can be defined as

$$
P_{t r}=\left\{s_{1}, s_{2}, \cdots, s_{\mathrm{m}} \cdots, s_{c_{p h}}\right\}
$$




$$
s_{m}=\left\{l_{s}^{m}, l_{e}^{m}, t_{s}^{m}, t_{e}^{m}, v_{s}^{m}, v_{e}^{m}, h_{s}^{m}, h_{e}^{m}, c u r^{m}, k^{m}\right\}, m \in\left[1, c_{p h}\right]
$$

where $P_{t r}$ is the set of traction phases of the train $t r . s_{m}$ is the information about the position $\left(l_{s}^{m}, l_{e}^{m}\right)$, moment $\left(t_{s}^{m}, t_{e}^{m}\right)$, speed $\left(v_{s}^{m}, v_{e}^{m}\right)$, curve radius $\left(c u r^{m}\right)$, longitudinal and cross-sectional elevation $\left(h_{s}^{m}, h_{e}^{m}\right)$, and type of traction phase $\left(k^{m}\right)$ corresponding to the phases. $c_{p h}$ is the number of traction phases contained in the train.

According to the above definition, the train status $g k_{i}^{t r}$ is detected one by one according to the time sequence. Through the designed corresponding relationship, the traction phase set can be obtained. The specific method is described in the next part.

\subsubsection{State-Based Traction Phase Detection Method}

According to the definition of the previous part, the traction phase segments of train operation can be aggregated according to the continuity of train operation state. TTD data can be used to comprehensively judge the traction phases according to acceleration, air duct pressure, engine speed, and other factors. When acceleration is positive and the engine is revving, it can be judged as traction; when the engine is not revving and the duct pressure is high, it can be judged as coasting; when the engine is not revving and the duct pressure is low, it can be judged as braking. (When the train needs to brake, the driver will turn the brake valve in the cab to the brake position to exhaust air, so as to reduce the air pressure of the train pipe. When the pressure of the auxiliary air cylinder of the train is greater than that of the train pipe, the slide valve is pushed to move so that the air in the auxiliary air cylinder enters the brake cylinder so as to push the brake shoe to generate braking force on the wheel and complete the braking operation.) Based on this, the mapping relationship for the traction phases can be designed as shown in Table 3.

Table 3. Mapping relationship between train operation status and traction phases.

\begin{tabular}{cc}
\hline Train Status Information & Traction Phases \\
\hline Acceleration is positive and the engine is revving. & Acceleration \\
The engine is not revving and the duct pressure is high. & Coasting \\
The engine is not revving and the duct pressure is low. & Braking \\
\hline
\end{tabular}

Under the premise of known TTD data and longitudinal and cross-sectional data, the running status of trains is detected one by one according to the chronological order of data points. If the train status has not changed, detection continues; if the train status has changed, the time and speed information of the current traction phase are recorded, and the detection of a new traction phase begins. The pseudo code of this process is shown in Algorithm 1.

After processing by this algorithm, the original discrete data are aggregated into three main traction phases: acceleration (TA), coasting (CO), and braking (TB), which are then noise-cleaned and ready for energy consumption calculation. 


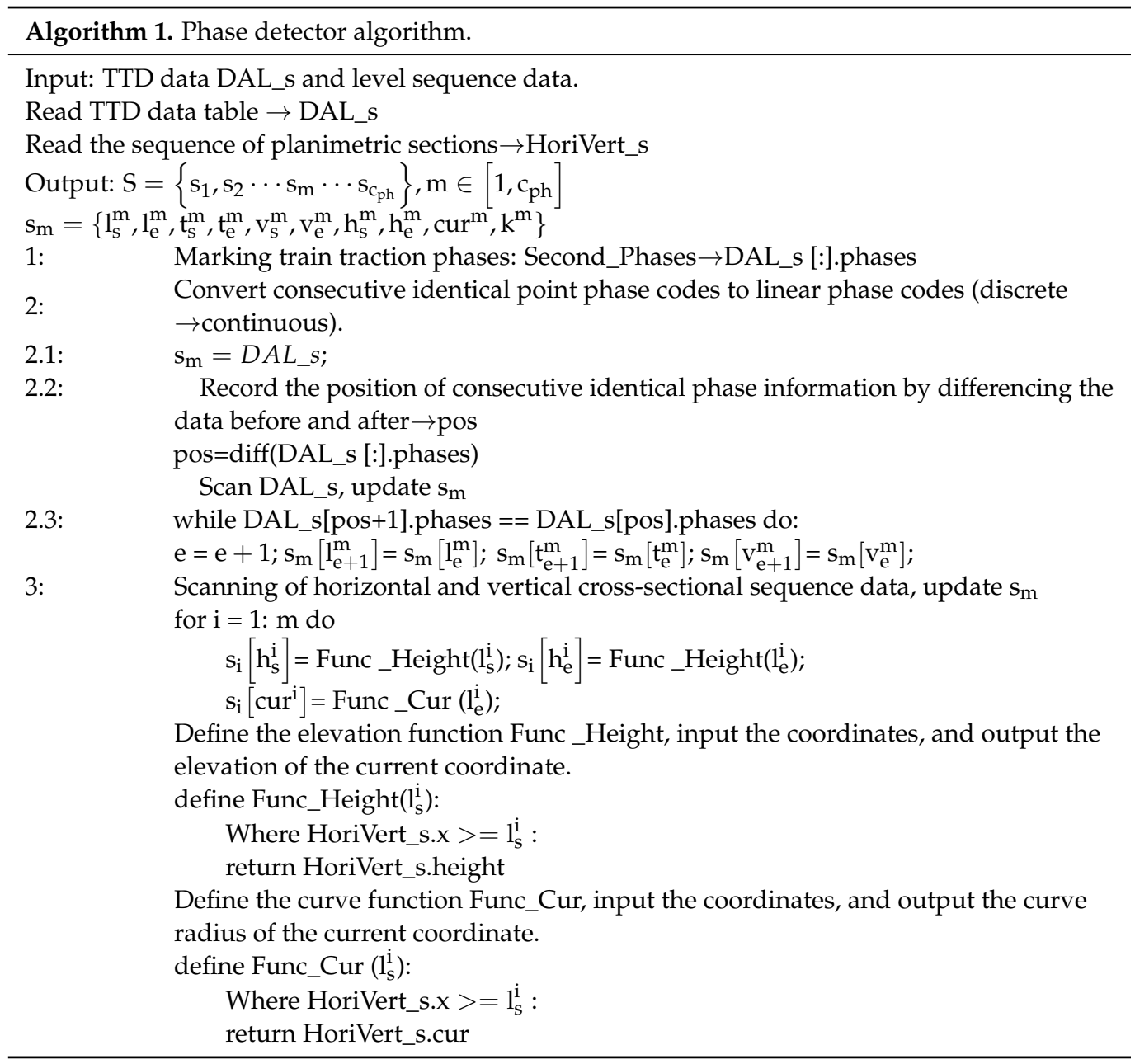

\subsection{TTD Data Noise Cleaning for Each Traction Phase}

The position, speed, and other sensors in the TTD device have some noise in the actual production environment. The anomalous data caused by this noise have a large impact on the energy consumption calculation, so this paper used the Kalman filter to correct the data in each section of the traction phases based on the identification of traction phases to improve the credibility of the energy consumption calculation results.

Train operation is a dynamic process operated by the driver. Whenever the train status changes (such as cylinder pressure, tube pressure change, locomotive traction phase change, traction current change, etc.), the TTD device will automatically record a set of data. Based on the observation, there is a large number of jagged microscopic adjustment details in the data. On the basis of ensuring accuracy, in order to simplify the calculation process, this part assumes that the locomotive can be regarded as a uniformly accelerated motion when it is under the same traction phase. According to this hypothesis, it is straightforward to use Newtonian mechanics to infer the change in train position and speed at different moments.

Let $\hat{x}_{t}^{-}$be the current state, i.e., the vector consisting of position $p_{t}$ and velocity $v_{t}$. When the state $\hat{x}_{t-1}^{-}$of the train at the previous moment $t-1$ is known, the state of the train at the current moment $t$ can be expressed according to the Newtonian mechanics formula as

$$
\hat{x}_{t}^{-}=\left[\begin{array}{c}
p_{t} \\
v_{t}
\end{array}\right]=\left[\begin{array}{cc}
1 & \Delta t \\
0 & 1
\end{array}\right]\left[\begin{array}{c}
p_{t-1} \\
v_{t-1}
\end{array}\right]+\left[\begin{array}{c}
\Delta t^{2} / 2 \\
\Delta t
\end{array}\right] u_{t}
$$

where $\Delta t$ is the step size of the stage and $u_{t}$ is the acceleration of the train in that stage. The equation can also be expressed as

$$
\hat{x}_{t}^{-}=F_{t} \hat{x}_{t-1}+B_{t} u_{t}
$$


where $F_{t}$ is the state transfer matrix $\left[\begin{array}{cc}1 & \Delta t \\ 0 & 1\end{array}\right]$, and $B_{t}$ is the control matrix $\left[\begin{array}{c}\Delta t^{2} / 2 \\ \Delta t\end{array}\right]$.

The acceleration $u_{t}$ of the train in this phase can be calculated by using the speed of the train at $t-2$ and $t-1$.

$$
u_{t}=\left(v_{t-1}-v_{t-2}\right) / \Delta t
$$

According to the Kalman filter principle, the covariance matrix can be used to represent the correlation between position and velocity, denoted by $\Sigma_{t}^{-}$. This correlation is corrected at each moment by the correlation $\Sigma_{t-1}$ of the previous moment and the noise $Q$, which can be expressed as

$$
\Sigma_{t}^{-}=F_{t} \Sigma_{t-1} F_{t}^{T}+Q
$$

The sensor data are assumed to obey a Gaussian distribution, the noise $Q$ is represented by the covariance $\mathrm{R}$, and the mean value $y_{t}$ of the Gaussian distribution is the read TTD data. The previously derived state projections are corrected based on the observations, and then

$$
\hat{x}_{t}=\hat{x}_{t}^{-}+K_{t}\left(y_{t}-\hat{x}_{t}^{-}\right)
$$

where $K_{t}$ is the weighted matrix for predicted residuals.

$$
K_{t}=\Sigma_{t}^{-}\left(\Sigma_{t}^{-}+R\right)^{-1}
$$

$K_{t}$ first weighs the magnitude of the predicted state covariance matrix $\Sigma$ and the observed value matrix covariance $R$, and uses this to control whether the cleaning results favor the predicted model or the actual observed model. If the predictive model is favored, the data are cleaned more intensely and the cleaned data tend to be flat; conversely, the actual observed model is favored and the noise points can be tolerated and retained. The above process can be described by pseudo-code, expressed as shown in Algorithm 2.

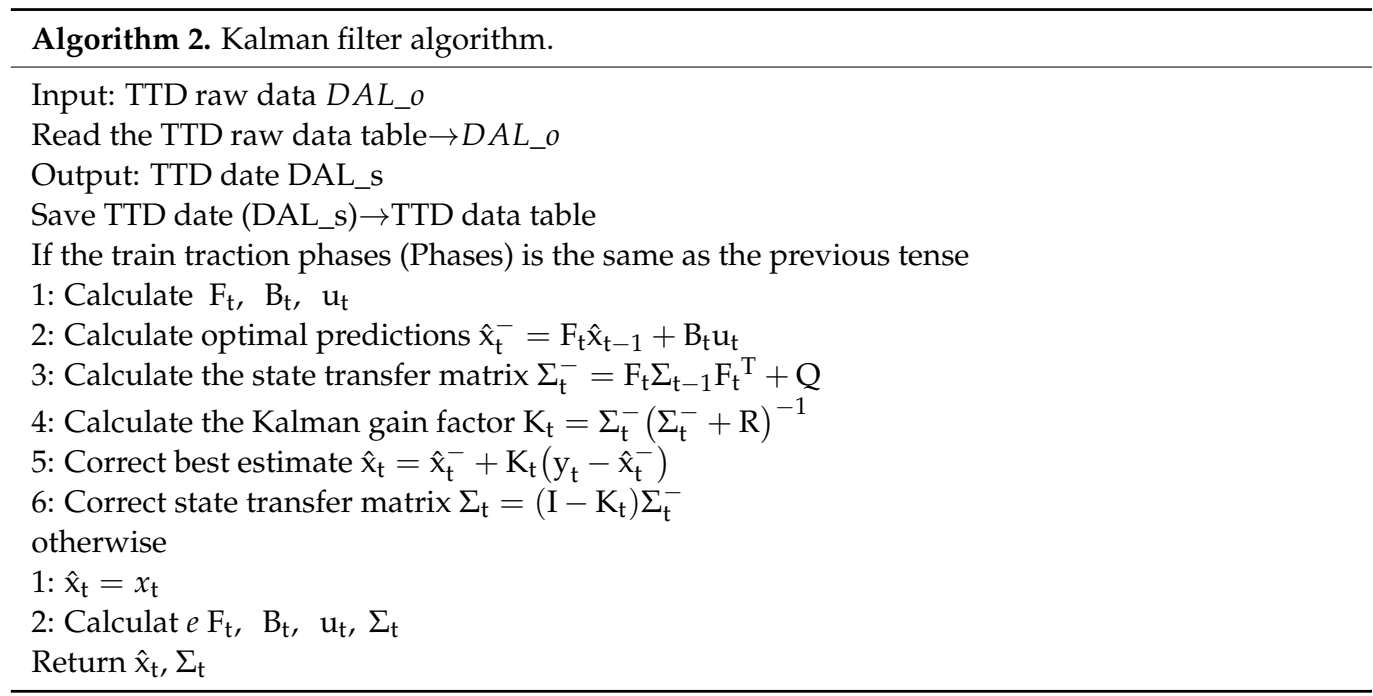

According to the above method, the noise of the TTD series data contained within each traction phase can be cleaned, and all the preparatory work before the energy consumption calculation is completed.

\subsection{Method of Calculating Energy Consumption for Each Traction Phase}

In this paper, according to the data obtained from the survey, the method introduced above was used to preprocess the data and detect the existing traction phases. This part calculates energy consumption by dynamic differential equations based on different traction phases (acceleration, coasting, braking). The energy consumption in each traction phase mainly includes (1) work done to overcome the train running resistance during train 
operation, (2) work done to overcome gravity, (3) increase in kinetic energy of the train, and (4) energy consumption of on-board equipment and other energy consumption. Since the energy consumption of on-board equipment and other energy consumption can be calculated according to the "Train Traction Calculation Regulations," this part of the study treats them as known quantities.

The energy consumption calculation methods for different traction phases are as follows:

1. Acceleration

During acceleration, the train locomotive converts the electrical energy in the grid into mechanical and internal energy. According to the principle of energy conservation and function, the energy consumption of train operation is equivalent to the sum of the mechanical energy change and the work done to overcome the total running resistance $E_{i, P}^{A}$ under the consideration of motor conversion efficiency $\eta^{i}$. The functional transformation equation during the train operation can be described as follows:

$$
\begin{gathered}
E_{i, P}^{A}=\frac{1}{\eta^{i}}\left(0.5 \cdot M^{i}\left(v_{e}^{c_{p h}}-v_{s}^{12}\right)+\sum_{m}\left(w_{0}^{i}\left(M^{i}-M_{0}^{i}\right)+w_{0}^{\prime i} M_{0}^{i}\right) \cdot\left(l_{e}^{m}-l_{s}^{m}\right)\right. \\
\left.+M^{i} g\left(h_{e}^{m}-h_{s}^{m}\right)+\sum_{m}\left(c u r^{m} \cdot w_{r}^{i} M^{i}\right) \cdot\left(l_{e}^{m}-l_{s}^{m}\right)+U I_{0}^{i}\left(t_{e}^{c_{p h}}-t_{s}^{1}\right)\right) \\
w_{0}^{i}=a+0.5 \cdot b\left(v_{e}^{c_{p h}}+v_{s}^{1}\right)+0.25 \cdot c\left(v_{e}^{c_{p h}}+v_{s}^{1}\right)^{2} \\
w_{0}^{\prime i}=a^{\prime}+0.5 \cdot b^{\prime}\left(v_{e}^{c_{p h}}+v_{s}^{1}\right)+0.25 \cdot c^{\prime}\left(v_{e}^{c_{p h}}+v_{s}^{1}\right)^{2} \\
w_{r}^{i}=600
\end{gathered}
$$

where $M^{i}$ is the total mass of train $i, M_{0}^{i}$ is the mass of train $i$ locomotive, $v_{e}^{c_{p h}}$ is the final speed of train operation, $v_{s}^{1}$ is the initial speed of train operation, $w_{0}^{i}$ is the unit basic resistance of train $i$ vehicle, $w_{0}^{\prime i}$ is the unit basic resistance of train $i$ locomotive, $w_{r}^{i}$ is the additional resistance of train $i$ curve, $g$ is the neutral acceleration, $l_{s}^{m}$ is the $m$ th traction phase starting mileage position, $l_{e}^{m}$ is the $m$ th traction phase ending mileage position, $h_{s}^{m}$ is the $m$ th traction phase starting position elevation, $h_{e}^{m}$ is the $m$ th traction phase ending position elevation, $\mathrm{cur}^{m}$ is the $m$ th traction phase curve radius, $t_{s}^{1}$ and $t_{e}^{c_{p h}}$ are the train running start and end time, $U$ is the supply voltage, and $I_{0}^{i}$ is the self-consumption of electricity.

The train running resistance includes basic running resistance and additional resistance. The first half of the formula $a+0.5 \cdot b\left(v_{e}^{c_{p h}}+v_{s}^{1}\right)$ is the basic resistance, which mainly includes the mechanical frictional resistance between the wheel axle and the wheel rail; the second half of the formula, $0.25 \cdot c\left(v_{e}^{c_{p h}}+v_{s}^{1}\right)^{2}$, is the additional resistance, mainly air resistance, which has a square relationship with the running speed of the train, and is a quadratic polynomial with speed as an independent variable.

According to the railway traction calculation industry standard, empirical parameters can be used as the additional resistance $w_{r}^{i}$ of the curve.

\section{Coasting}

In the coasting phase, since the locomotive motor no longer applies tractive force, the tractive force does not do work and the train does work at the cost of mechanical energy (kinetic energy plus potential energy) consumption to overcome the train running resistance. Therefore, the energy consumption of the train only needs to consider the selfconsumption of electricity by the locomotive instrumentation, and the specific expression is as follows:

$$
E_{i, P}^{C}=\frac{1}{\eta^{i}} U I_{0}^{i}\left(t_{e}^{c_{p h}}-t_{s}^{1}\right)
$$


where $E_{i, P}^{C}$ is the energy consumption value of train coasting phase, $\eta^{i}$ is the motor conversion efficiency, $t_{s}^{1}$ and $t_{e}^{c_{p h}}$ are the train running start and stop times, respectively, $U$ is the supply voltage, and $I_{0}^{i}$ is the self-consumption of electricity.

\section{Braking}

As the braking method of the train studied in this paper is mainly gate braking and air braking, the motor does not output tractive force during the braking process, and the tractive force does not do any work. Therefore the train energy consumption only needs to consider the locomotive instrumentation self-use electricity consumption. The specific expression is as follows:

$$
E_{i, P}^{B}=\frac{1}{\eta^{i}} U I_{0}^{i}\left(t_{e}^{c_{p h}}-t_{s}^{1}\right)
$$

where $E_{i, P}^{B}$ is the energy consumption value of the train braking phase, $\eta^{i}$ is the motor conversion efficiency, $t_{s}^{1}$ and $t_{e}^{c_{p h}}$ are the train running start and stop times, respectively, $U$ is the supply voltage, and $I_{0}^{i}$ is the self-consumption of electricity.

\section{Total Energy Consumption}

According to the above three train operation traction phases, the calculated $E_{i}$ can be regarded as the energy consumption generated by the train during operation, and $A, B$ and $\mathrm{C}$ are the acceleration, braking, and coasting phases, respectively.

$$
E_{i}=\sum_{s_{m} \in P} E_{i, P} \quad E_{i, P}=\left\{\begin{array}{l}
E_{i, P}^{A}, k=A \\
E_{i, P}^{C}, k=C \\
E_{i, P}^{B}, k=B
\end{array}\right.
$$

According to the above steps, the energy consumption data of each train can be mined and calculated based on the TTD data.

\subsection{Multi-Dimensional Energy Consumption Distribution Model}

Based on the above method, the energy consumption data of a single train can be obtained. Based on the assumption of Gaussian distribution, this part condenses the energy consumption standards contained therein to form a multi-dimensional distribution model for reference. The dimensions that determine the energy consumption include the train tonnage rating, different train groups, travel paths, the stopping scheme, etc. By calculating the traction energy consumption of trains according to different running modes, the influence of various conditions on the traction energy consumption of trains such as different destinations, different time periods, different sections, different fixed numbers, different stopping schemes, and different running speeds can be obtained. The above seven dimensions can be expressed as $x_{e c}$ :

$$
x_{\mathrm{ec}}=\left\{x_{O}, x_{D}, t_{O}, t_{D}, w e i, s t, v_{\text {tra }}\right\} \in X
$$

where $x_{O}$ and $x_{D}$ represent the departure and arrival stations of the train, respectively, $t_{O}$ and $t_{D}$ refer to the start and end time of the train operation, respectively, wei indicates the combination of train (including long-form train, short-form train, and empty train mode), st takes the value to represent different stopping schemes of the train, and $v_{\text {tra }}$ indicates the train operation speed, which refers to the train operation in the section, excluding the stopping time of intermediate stations and the additional time of starting and stopping. E represents the energy consumption of a specific train under certain data conditions. 
Let the individual energy consumption utilization of trains in the same dimension obey a Gaussian distribution, whose probability density function is noted as $E_{x_{\mathrm{ec}}} \sim N\left(\mu, \sigma^{2}\right)$ and can be expressed as:

$$
\begin{gathered}
E_{x_{\mathrm{ec}}} \sim N\left(\mu_{x_{\mathrm{ec}}}, \sigma_{x_{\mathrm{ec}}}\right)=\frac{1}{\sqrt{2 \pi} \sigma_{x_{\mathrm{ec}}}} \exp \left(-\frac{\left(w-\mu_{x_{\mathrm{ec}}}\right)^{2}}{2 \sigma_{x_{\mathrm{ec}}}^{2}}\right) \in E \\
\text { Dimension }(E)=\left|X_{O}\right| \times\left|X_{D}\right| \times\left|T_{O}\right| \times\left|T_{D}\right| \times \mid \text { Wei }|\times| S t|\times| V_{\text {tra }} \mid
\end{gathered}
$$

Through data fitting techniques, the mean $\mu$ and variance $\sigma^{2}$ of the energy consumption in different dimensions can be obtained to construct Gaussian distribution models. The resulting multi-dimensional distribution model dimensions are shown above.

\section{Optimization Transportation Plans Considering Capacity and Energy Consumption}

Considering constraints such as line interval passing capacity, station loading and unloading capacity, and combined dismantling capacity, this section calculates the energy consumption of trains on different routes based on the results of Section 2, and constructs an optimization model to obtain plans that can balance energy consumption and capacity utilization. An algorithm is designed to solve the model.

\subsection{Model Building}

\subsubsection{Notation Definition}

Before defining the parameters, the problem was first hypothesized and the scope of the study was defined.

Rail transportation is based on a $24 \mathrm{~h}$ decision cycle. Considering the scale of computing, it is necessary to divide the day into time periods expressed in several minutes, and in each time period the physical stations are replicated and expanded, and so on, forming a time-space network of nodes corresponding to the departure and arrival of heavy trains at each station at any given moment. The lines are assumed to be double lines, and the combined operation of long and short trains can only be performed in the combined stations. Under such assumptions, the relevant knowledge of graph theory was applied to the modeling analysis.

The key to solving the transportation organization optimization problem was to obtain the train operation plan and the specific transportation path for each demand. In view of this, the variables $y_{(i, j, t, t p, s)}$ expressing the train operation plan and the transport path guidance variables $x_{i, j, k, t}^{(i, j, t, t, s)}$ for demand were designed, and the specific meanings are shown in Table 4. Among them, the upper corner markers $(i, j, t, t p, s)$ in the transport path guidance variables $x_{i, j, k, t}^{(i, j, t, t p, s)}$ for demand contained both the possible train arcs $A^{S}$ to take and the waiting arcs $A^{C W}$ for loading or unloading, the stopping arcs $A^{C H}$ after loading is completed, and the transfer arcs $A^{C T}$ at the combination stations. 
Table 4. Model notation.

\begin{tabular}{|c|c|}
\hline Notation & Descriptions \\
\hline$N$ & Station collection, indexed as $i, j, n$. \\
\hline$N^{Z}$ & Assembly of combination stations. \\
\hline$E$ & Collection of sections in track. \\
\hline$P$ & $\begin{array}{l}\text { A collection of transportation requirements which, for each requirement, contains } \\
\text { the starting station } i \text { and the ending station } j \text { and the corresponding sequence } \\
\text { number } k,(i, j, k) \in P .\end{array}$ \\
\hline$A^{S}$ & $\begin{array}{l}\text { A collection of train services at the service level; each service contains } o_{s}, d_{s}, t_{o_{s}}, t_{d_{s}} \text {, } \\
\text { which are the start station, end station, start time, and end time, respectively. }\end{array}$ \\
\hline$A^{C W}$ & $\begin{array}{c}\text { Waiting arc planning at the demand level, including waiting for loading and waiting } \\
\text { for unloading. }\end{array}$ \\
\hline$A^{C H}$ & $\begin{array}{c}\text { Dwell arc after loading at the demand floor, dwell arc after changing trains at the } \\
\text { combination station, etc. }\end{array}$ \\
\hline$A^{C T}$ & $\begin{array}{c}\text { Demand layer interchange arcs for two successive train services at the combination } \\
\text { station. }\end{array}$ \\
\hline$A$ & $\begin{array}{l}\text { The sum of all arcs in the requirements and service layers, } \mathrm{A}= \\
A^{S} \cup A^{C W} \cup A^{C H} \cup A^{C T} \text {, where a is the index variable of the arc set. }\end{array}$ \\
\hline$A_{n}^{+}, A_{n}^{-}$ & Represent the out-arc and in-arc sets of all time nodes of node n, separately. \\
\hline$A_{n, t}^{+}, A_{n, t}^{-}$ & Represent the set of out-arc and in-arc nodes $n$ at time $t$, separately. \\
\hline K & $\begin{array}{l}\text { The demand between each demand loading and unloading node is divided into a } \\
\text { set of unit volumes, with } \mathrm{k} \text { as its index variable. }\end{array}$ \\
\hline$d_{i j}$ & Total coal demand from $\mathrm{i}$ to $\mathrm{j}$. \\
\hline$y_{i j}^{k}$ & $\begin{array}{l}\text { Whether the kth branch of demand between I and j is successfully shipped, if so, } \\
\qquad y_{i j}^{k}=1 \text {, otherwise } y_{i j}^{k}=0 .\end{array}$ \\
\hline$C_{e}$ & Passing capacity as arc e. \\
\hline$C_{S}$ & $\begin{array}{c}\text { The loading capacity of train s, with a value of } 1 \text { or } 2 \text {, representing the short-form } \\
\text { train and long-form train, respectively. }\end{array}$ \\
\hline$\tau_{i j k}$ & $\begin{array}{l}\text { The node in time between } \mathrm{i} \text { and } \mathrm{j} \text { when the coal demand is ready to be loaded and } \\
\text { shipped at any time, with the ability to ship at each integer. }\end{array}$ \\
\hline$t_{i j k}$ & Denotes the average transport time of this tributary $(i, j, k)$. \\
\hline$a$ & $\begin{array}{c}\text { The arc a in the time-space network is denoted by }(i, j, t, t p, s) \text {, and the five symbols } \\
\text { in parentheses denote the original station, destination station, departure time, } \\
\text { arrival time, and train properties of the arc, respectively. }\end{array}$ \\
\hline$e$ & Run segment, denoted by $(i p, j p)$ \\
\hline$\mu_{n}$ & Maximum combined capacity of combined station $\mathrm{n}$ per unit time (time window). \\
\hline$\delta_{(i p, j p)}^{(i, j, t, t p, s)}$ & $\begin{array}{l}0-1 \text { associated variable, with a value of } 1 \text { if } t \text { of the physical segment }(i p, j p) \text { is } \\
\text { passed by the train service arc }(i, j, t, t p, s) \delta_{(i p, j p)}^{(i, j, t, t p, s)}=1 \text {, otherwise } \delta_{(i p, j p)}^{(i, j, t, t p, s)}=0\end{array}$ \\
\hline$\omega_{(i, j, s)}$ & The $\operatorname{arc}(i, j, s)$ is the cost of running the train in service, $\forall a \in A^{S}$ \\
\hline$v_{(i, j, s)}$ & $\operatorname{Arc}(i, j, s)$ is the interchange cost for combined station transfers. \\
\hline$\zeta_{(i, j, s)}$ & $\operatorname{Arc}(i, j, s)$ is the energy cost of the service train. \\
\hline$\xi_{(i, j, s)}$ & $\operatorname{Arc}(i, j, s)$ is the interchange energy cost for the combined station transfer. \\
\hline$\gamma$ & Conversion factor per unit of time to other costs. \\
\hline$y_{(i, j, t, t p, s)}$ & $\begin{array}{c}0-1 \text { decision variable, if } y_{(i, j, t, t p, s)}=1 \text { and }(i, j, t, t p, s) \in A^{S} \text {, then it means that train } \\
\text { service }(i, j, t, t p, s) \text { is used; if }(i, j, t, t p, s) \in A^{C T} \text {, then it means that commutation } \\
\text { arc }(i, j, t, t p, s) \text { is used; otherwise } y_{(i, j, t, t p, s)}=0 \text {. }\end{array}$ \\
\hline$x_{i, j, j, t}^{(i, j, t, t p, s)}$ & $\begin{array}{l}\text {-1 decision variables, representing the demand generated at moment } t \text { from } i \text { to } j \\
\text { numbered } \mathrm{k} \text { by train service }(i, j, t, t p, s) \text { transport then } x_{i, j, k, t}^{(i, j, t, t p, s)}=1 \text {, otherwise } \\
\qquad x_{i, j, k, t}^{(i, j, t, t p, s)}=0 .\end{array}$ \\
\hline
\end{tabular}

After determining the decision variables, a series of constraints was constructed, such as flow balance constraints, line and station capacity constraints, decision variables association constraints, combination station combination capacity constraints, combination train succession time constraints, etc., so as to form the transportation organization optimization model of the network flow optimization theory. The parameters involved in the model are detailed in Table 4. 


\subsubsection{Objective Function}

The objective function considering the optimization of heavy-haul railway transportation organization in the coal lanes includes (1) travel distance cost, (2) energy consumption cost of heavy trains, and (3) running time cost, where objectives 1 and 3 represent capacity utilization and objective 2 represents energy consumption. Among them, the travel time and distance cost parameters can be obtained from the actual operation data, and the energy consumption cost parameters are obtained by using the analysis results in Section 2.

(1) The cost of distance traveled by heavy trains is divided into two parts; one is the cost of the actual travel process, and the other is the economic cost of the combined operation.

$$
Z_{1}=\sum_{a \in A^{S}} y_{(i, j, t, t p, s)} \omega_{(i, j, s)}+\sum_{a \in A^{C T}} y_{(i, j, t, t p, s)} v_{(i, j, s)}
$$

where $\omega_{(i, j, s)}$ denotes the running cost when arc $(i, j, s)$ is a train; $v_{(i, j, s)}$ denotes the walking cost incurred when arc $(i, j, s)$ combines station interchange arcs.

(2) The energy cost of heavy train transportation is divided into two parts; one is the energy cost spent during the actual travel and the other is the energy cost spent in the combined operation.

$$
Z_{2}=\sum_{a \in A^{S}} y_{(i, j, t, t, p, s)} \zeta_{(i, j, s)}+\sum_{a \in A^{C T}} y_{(i, j, t, t p, s)} \xi_{(i, j, s)}
$$

where $\zeta_{(i, j, s)}$ denotes the energy consumption cost when arc $(i, j, s)$ is a train arc; $\xi_{(i, j, s)}$ denotes the energy consumption cost incurred when $\operatorname{arc}(i, j, s)$ is an interchange arc of a combined station.

(3) The running time span costs accounted for by the train operation plan. The parameter $\gamma$ converts the time into other costs by putting energy consumption costs and the travel distance costs on the same scale.

$Z_{3}=\gamma \cdot \min \left\{\max _{(i, j, t, t p, s), j=N}\left\{t p \cdot y_{(i, j, t, t p, s)}\right\}-\min _{(i, j, t, t p, s), i=1}\left\{t \cdot y_{(i, j, t, t, t, s)}\right\}\right\}$

The total objective function can be expressed as follows:

$$
Z=\lambda_{1} Z_{1}+\lambda_{2} Z_{2}+\lambda_{3} Z_{3}
$$

and

$$
\lambda_{1}+\lambda_{2}+\lambda_{3}=1
$$

\subsubsection{Constraints}

(1) Flow balance constraint. For an arbitrary demand $(o, d, t p p, k)$, the transport path should be guaranteed to have a beginning and an end, as well as continuity in the path. The following three equations establish the flow balance constraints for the start node, intermediate nodes, and end node, respectively.

$$
\begin{gathered}
\sum_{a \in A_{o, t}^{+}, t=t p p} x_{(o, d, t p p, k)}^{(0, j, t, t p, s)} \leq 1, \forall(o, d, t p p, k) \in P \\
\sum_{a \in A_{n, t}^{-}, t \geq t p p} x_{(o, d, t, t p, k)}^{(i, n, t p, t, s)}=\sum_{a \in A_{n, t}^{+}, t \geq t p p} x_{(o, d, t, t p p, k)}^{(n, j, t, t p)} \cdot \forall n \in N \backslash\{0, d\}, \forall(o, d, t p p, k) \in P \\
\sum_{a \in A_{i, t}^{+}, t=t p p} x_{(o, d, t p p, k)}^{(i, j, t, t p, s)}=\sum_{a \in A_{j, t}^{-}, t \geq t p p+t_{o d}} x_{(0, d, t p p, k)}^{(i, j, t p, t, s)} \forall(o, d, t p p, k) \in P
\end{gathered}
$$


(2) Establish a connection between the decision variables $y$ and $x . y$ is used to indicate whether an arc is used or not, and $x$ is used to indicate whether a demand is conveyed by a certain arc.

$$
x_{(o, d, t p p, k)}^{(i, j, t, t p, s)} \leq y_{(i, j, t, t p, s)}, \forall(i, j, t, t p, s) \in A^{S} \cup A^{C T}, \forall(o, d, t p p, k) \in P
$$

(3) Train loading capacity constraint. This cannot exceed the number of trains available for supply.

$$
\sum_{(o, d, t p p, k) \in P} x_{(o, d, t p p, k)}^{(i, j, t, t p, s)} \leq s * y_{(i, j, t, t p, s)}, \forall(i, j, t, t p, s) \in A^{S}
$$

(4) Combination station combination capacity constraint. During any time period, the combination station $\mathrm{n}$ completed operations cannot exceed the combination capacity of the station.

$$
\begin{aligned}
& \sum(n, j, t, t p, 2) \in A_{n, t}^{+} \cap A^{S} \quad y_{(n, j, t, t p, 2)} \leq \mu_{n}, \forall n \in N^{Z} \cdot \forall t_{0} \in[0, T] \\
& t \in\left[t_{0}, t_{0}+1 h\right]
\end{aligned}
$$

(5) The section passing capacity constraint. For any section e, the number of trains released in a given time period cannot exceed the maximum passing capacity constraint of the section.

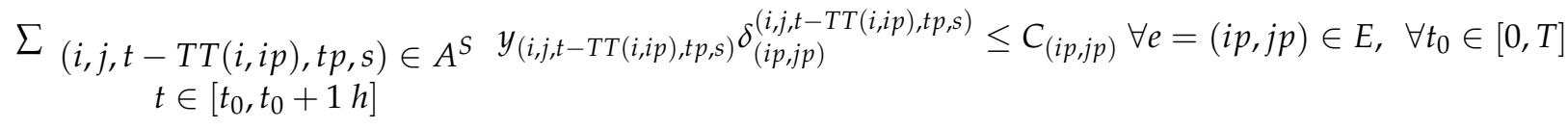

(6) At a station, only one train can leave at most during a time period.

$$
\sum_{(i, j, t, t p, s) \in A_{i, t}^{+} \cap A^{S}} y_{(i, j, t, t p, s)} \leq 1 \forall i \in N \forall t \in[0, T]
$$

(7) At a station, only one train can arrive at most during a time period.

$$
\sum_{(j, i, t p, t, s) \in A_{i, t}^{-} \cap A^{S}} y_{(j, i, t p, t, s)} \leq 1 \forall i \in N \forall t \in[0, T]
$$

(8) Headway time constraint for a combination operation. The necessary time should be left between two adjacent trains for a combination operation, and the waiting time should not be too long.

$\left|\sum_{\substack{(i, n, t p, t, 1) \in A_{n, t}^{-} \cap A^{S} \\ t \leq \tau}} t \cdot x_{(o, d, t p p, k)}^{(i, n, t p, t, 1)}-\sum_{\substack{(i, n, t p, t, 1) \in A_{n, t}^{-} \cap A^{S} \\ t \leq \tau}} t \cdot x_{(o p, d, t p p p, k p)}^{(i, n, t p, t, 1)}\right| \leq t_{\max }+M\left(1-x_{(o, d, t, t p p, k)}^{(n, d, \tau p, 2)} x_{(o p, d, t p p p, k p)}^{(n, d, \tau, \tau p, 2)}\right)$

$\forall(n, d, \tau, \tau p, 2) \in A^{S} \forall(o, d, t p p, k) \in P \forall(o p, d, t p p p, k p) \in P$

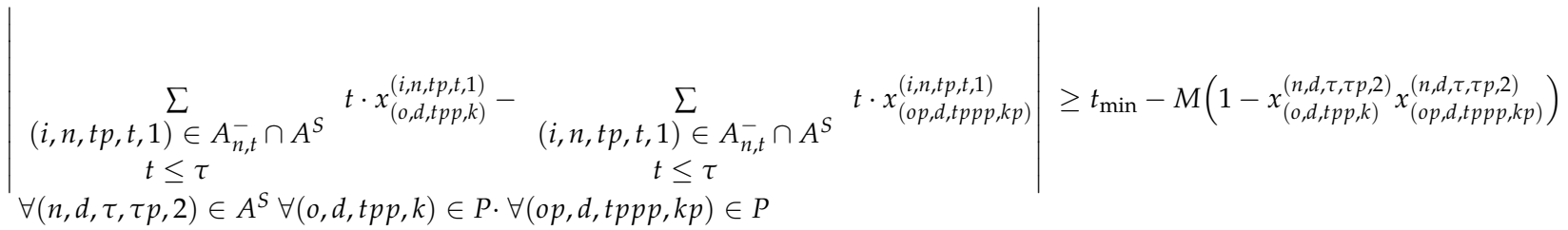

(9) Total demand constraint. The total amount of actual transportation should be exactly equal to the total amount of demand. 


$$
\sum_{t p p, k} \sum_{(o, j, t p p, t p, s) \in A^{S}} x_{(o, d, t p p, k)}^{(o, j, t p p, t p, s)}=d_{o d}
$$

\subsection{Branch-and-Bound Algorithm}

Based on the Section 3.1, train time-space route analysis, the mixed integer programming model, including energy consumption and capacity, was established, and a branch-and-bound algorithm was designed to solve the model. The algorithm pseudo-code is shown in Algorithm 3.

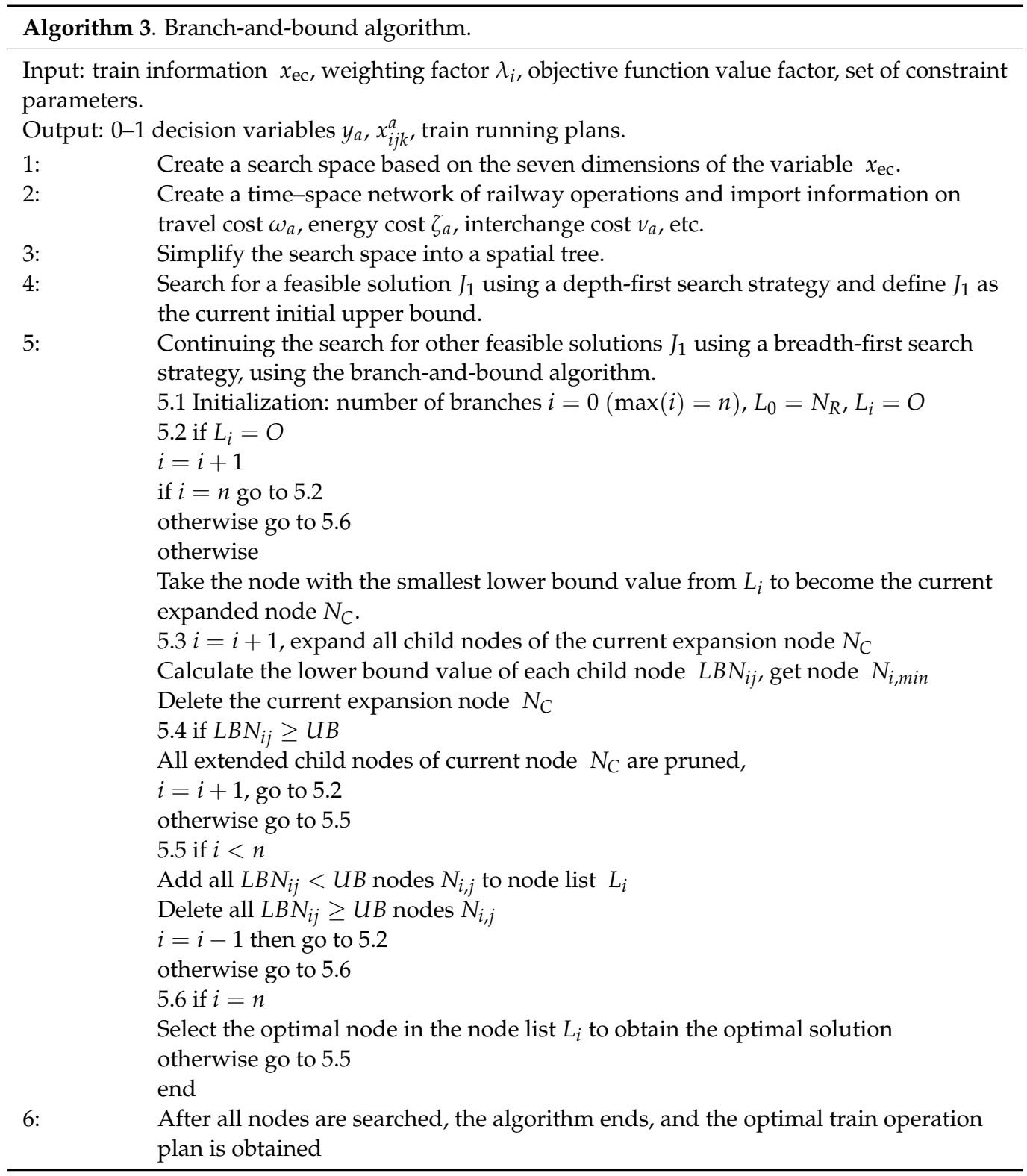

\section{Numerical Experiments}

In this paper, we calculated the actual energy consumption of trains operating on a line segment belonging to a group in northern China in November 2017. Among them, there were 23 stations on the main line excluding Station 25, of which there were four third-class stations, 19 fourth-class stations, and nine stations with 10,000 tons of feeder lines. The total length of the line was $264.6 \mathrm{~km}$, with a maximum restricted slope of $10.9 \%$ and a maximum speed limit of $82 \mathrm{~km} / \mathrm{h}$. 
In this paper, the data involved included (1) railway topology data, including railway lines and basic station data; (2) cross- and longitudinal section data, including line length, kilometer markers, gradient and curve radius, etc.; (3) TTD (train trajectory data) for that month. In Figure 2, Station 1-Station 25 is in the upstream direction whereas the opposite is downstream. Station 2, Station 3, Station 4, Station 9, Station 24, and Station 25 were the main loading stations, and trains mainly stopped at these stations. The types of trains included empty trains, short-form trains (50 units), and long-form train (100 units).

Schematic diagram of railway line

$(264.6 \mathrm{~km})$

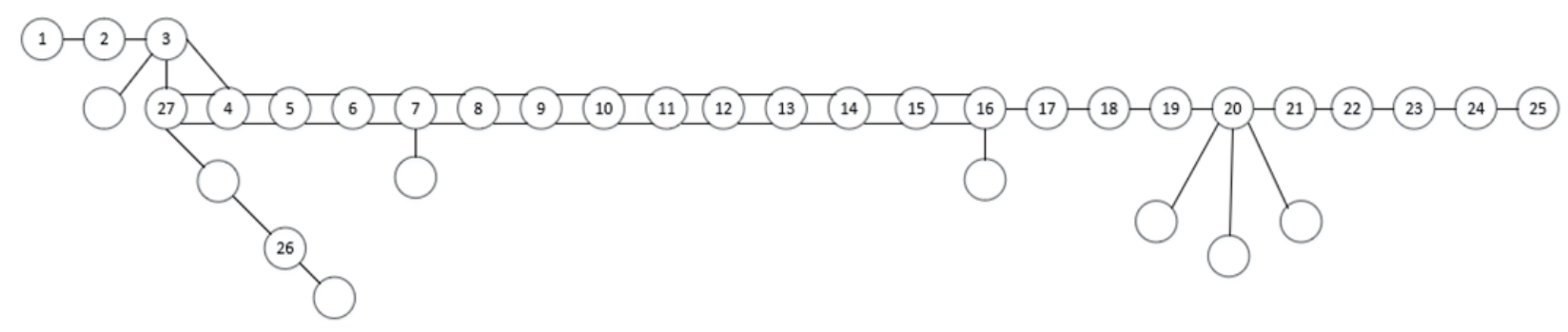

Figure 2. Diagram of a line belonging to a group in northern China.

The numerical experiment mainly included (1) energy consumption calculations and the construction of a multi-dimensional distribution model, (2) a comparison of the average energy consumption of long- and short-form trains, (3) the effect of departure interval on the energy consumption of long trains, and (4) an analysis of the capacity and energy consumption.

\subsection{Energy Consumption Calculations and Construction of Multi-Dimensional Distribution Model}

The data in different dimensions (train origin and destination, time period, onsegment, fixed number, stopping scheme, operating speed, etc.) were extracted and used to calculate the energy consumption and analyze energy consumption criteria using the methods mentioned in this section. Due to the large number of dimensions involved, this section takes the interval of Station 24-Station 2 as an example, and the scatter plots of energy consumption for empty trains, short-form trains (50 units), and long-form trains (100 units) in this interval are shown in Figure 3a-c. The observation shows that even in the same dimension, there were differences in the energy consumption of trains, which may be due to (1) the variability of drivers' driving behavior or (2) the variability due to the sparsity of train tracking in different time periods. The mean values of energy consumption excavation for different types of trains were $17,512.0 \mathrm{kw} \cdot \mathrm{h}$ (short-form trains), $9479.9 \mathrm{kw} \cdot \mathrm{h}$ (empty trains), and $51,351.6 \mathrm{kw} \cdot \mathrm{h}$ (long-form trains), which generally shows that the energy consumption of the long-form train was the highest, the energy consumption of the empty trains was the lowest, and the difference in energy consumption between different empty trains was the smallest. 


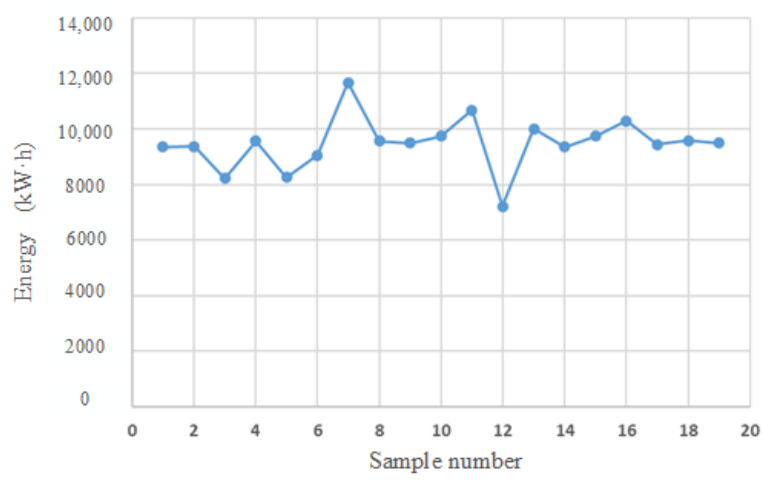

(a)

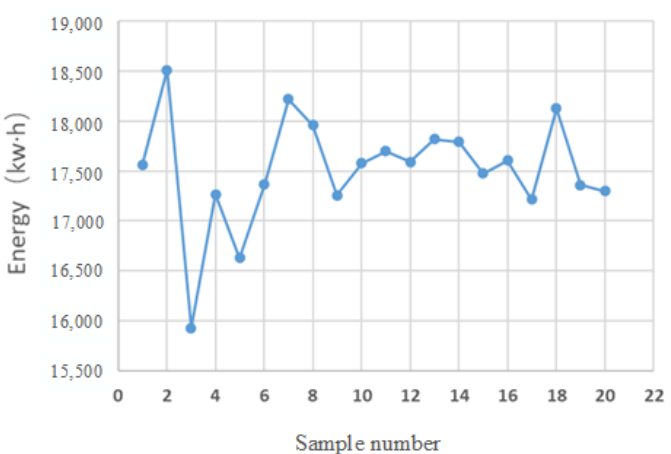

(b)

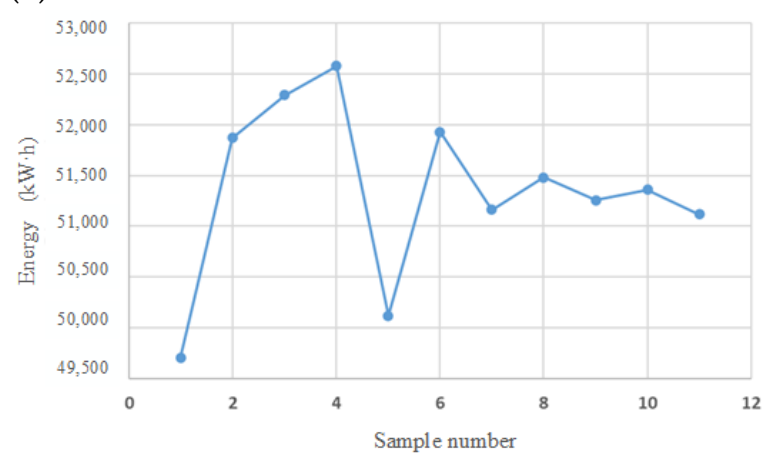

(c)

Figure 3. Scatter diagram of energy consumption $(\mathrm{kw} \cdot \mathrm{h})$ of trains. The study section range is Station $24-$ Station 2 (a) for the short-form train, (b) for the empty train, and (c) for the long-form train.

The data under different dimensions were fitted separately for Gaussian distribution, and the fitting was done according to the $3 \sigma$ criterion to determine the range, i.e., the set $\sigma$ could contain $99.74 \%$ of the values in the interval $[\mu-3 \sigma, \mu+3 \sigma]$. The energy consumption of the individual trains existing in actual operation was calculated and classified and aggregated according to the dimensions, and a series of energy consumption data sets were obtained. The mean $\mu$ and standard deviation $\sigma$ of energy consumption generated by train operation under some dimensions are shown in Table 5 . The original station and destination station included Station 2, Station 3, Station 4, Station 9, Station 24, and Station 25. The number of stops was distributed in the range of $0-6$, the train travel speed was concentrated in the range of $40-70 \mathrm{~km} / \mathrm{h}$, and the time period was in the range of $0-24 \mathrm{~h}$. The closer the value of $R^{2}$ was to 1 , the better the fitting effect was. The results show that $R^{2}$ was distributed between 0.69 and 0.87 , and the overall fitting results were acceptable. The reason for the low fit of some dimensions is that the amount of data in some dimensions in the actual data was not enough, which led to a lack of fit. 
Table 5. Mean $\mu$ and standard deviation $\sigma$ of energy consumption of train operation under partial conditions (energy unit: $\mathrm{kw} \cdot \mathrm{h})$.

\begin{tabular}{|c|c|c|c|c|c|}
\hline Train Form & Number of Stops & $\begin{array}{l}\text { OD (Volume from } \\
\text { Origin to Destination) }\end{array}$ & Average $\mu$ & Standard Deviation $\sigma$ & $R^{2}$ \\
\hline Empty train & 0 & Station 24-Station 2 & 9479.9 & 935.3 & 0.82 \\
\hline Empty train & 0 & Station 24-Station 4 & 8310.4 & 798.4 & 0.84 \\
\hline Empty train & 2 & Station 24-Station 3 & 8942.6 & 872.5 & 0.77 \\
\hline Empty train & 3 & Station 3-Station 24 & 9067.4 & 901.9 & 0.74 \\
\hline Short-form train & 3 & Station 24-Station 2 & $17,981.5$ & 1256.4 & 0.73 \\
\hline Short-form train & 3 & Station 25-Station 2 & $18,513.8$ & 1174.7 & 0.69 \\
\hline Short-form train & 4 & Station 25-Station 2 & $19,012.4$ & 1298.2 & 0.81 \\
\hline Short-form train & 0 & Station 2-Station 24 & $17,512.0$ & 557.3 & 0.79 \\
\hline Short-form train & 3 & Station 2-Station 25 & $18,513.7$ & 884.2 & 0.73 \\
\hline Long-form train & 0 & Station 2-Station 24 & $51,351.6$ & 856.17 & 0.82 \\
\hline Long-form train & 4 & Station 2-Station 24 & $56,922.2$ & 1679.8 & 0.87 \\
\hline Long-form train & 4 & Station 4-Station 25 & $55,848.2$ & 1567.2 & 0.74 \\
\hline Long-form train & 0 & Station 4-Station 24 & $51,480.9$ & 1351.5 & 0.77 \\
\hline Long-form train & 2 & Station 11-Station 24 & $34,047.8$ & 1058.6 & 0.75 \\
\hline
\end{tabular}

To show the form of the energy consumption criterion more concretely, Figure $4 a-c$ shows the Gaussian distribution of empty, short-form trains (50 units) and long-form trains (100 units) using the Station 24-Station 2 interval as an example. By fitting the curves, it was possible to achieve continuation of discrete data to support subsequent decisions on transportation organization plans.

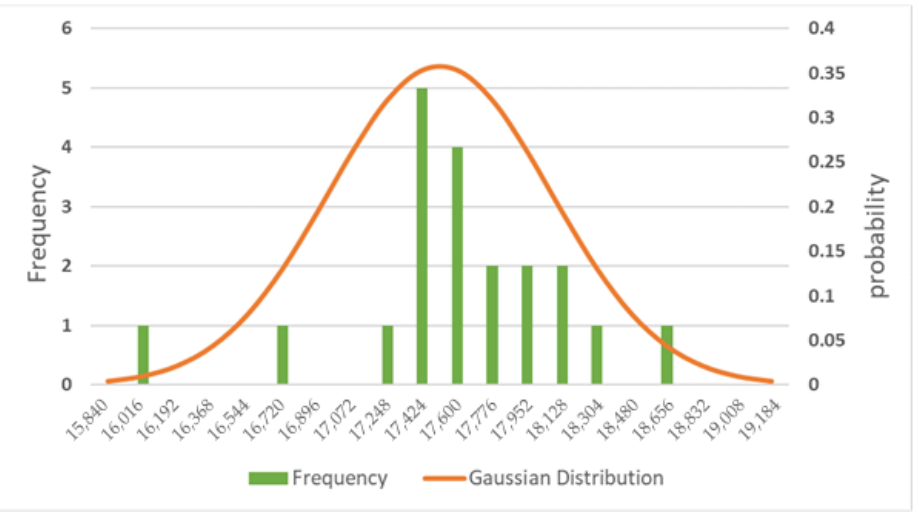

(a)

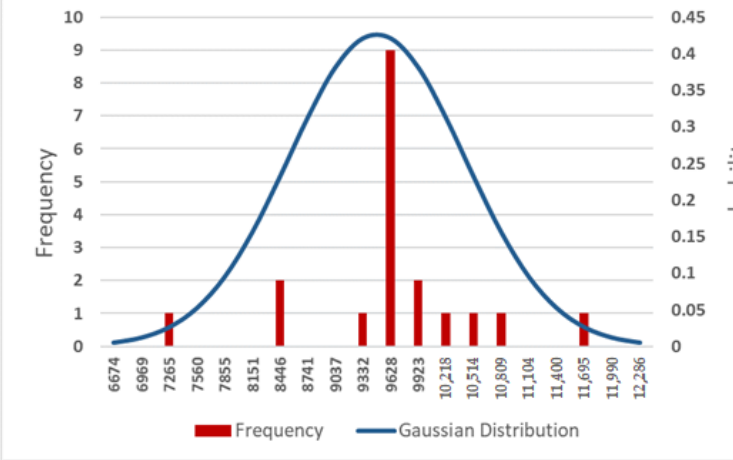

(b)

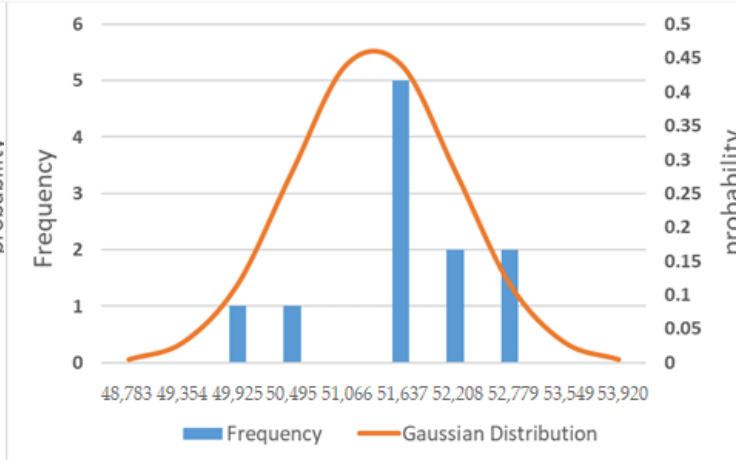

(c)

Figure 4. The Gaussian distribution of energy consumption in the Station 24-Station 2 interval, where (a) is for short-form trains, (b) is for empty trains, and (c) is for long-form trains. The standard deviations are $935.3 \mathrm{kw} \cdot \mathrm{h}$ (empty trains), $557.3 \mathrm{kw} \cdot \mathrm{h}$ (short-form trains), and $856.2 \mathrm{kw} \cdot \mathrm{h}$ (long-form trains). 
Observing the parallel axis diagram of the multi-dimensional distribution model, when only a single dimension was considered, there was a certain pattern of energy consumption: The more stops in the same type of train, the greater the energy consumption, and similarly, the higher the speed in the same type of train, the greater the energy consumption, which is consistent with general common sense. However, when different combinations of dimensions were considered, the energy consumption distribution showed a staggered shape, and the relationship between its size and dimensionality was more complicated. Energy consumption distribution patterns of the upper and lower trains in seven dimensions are shown in Figure 5.

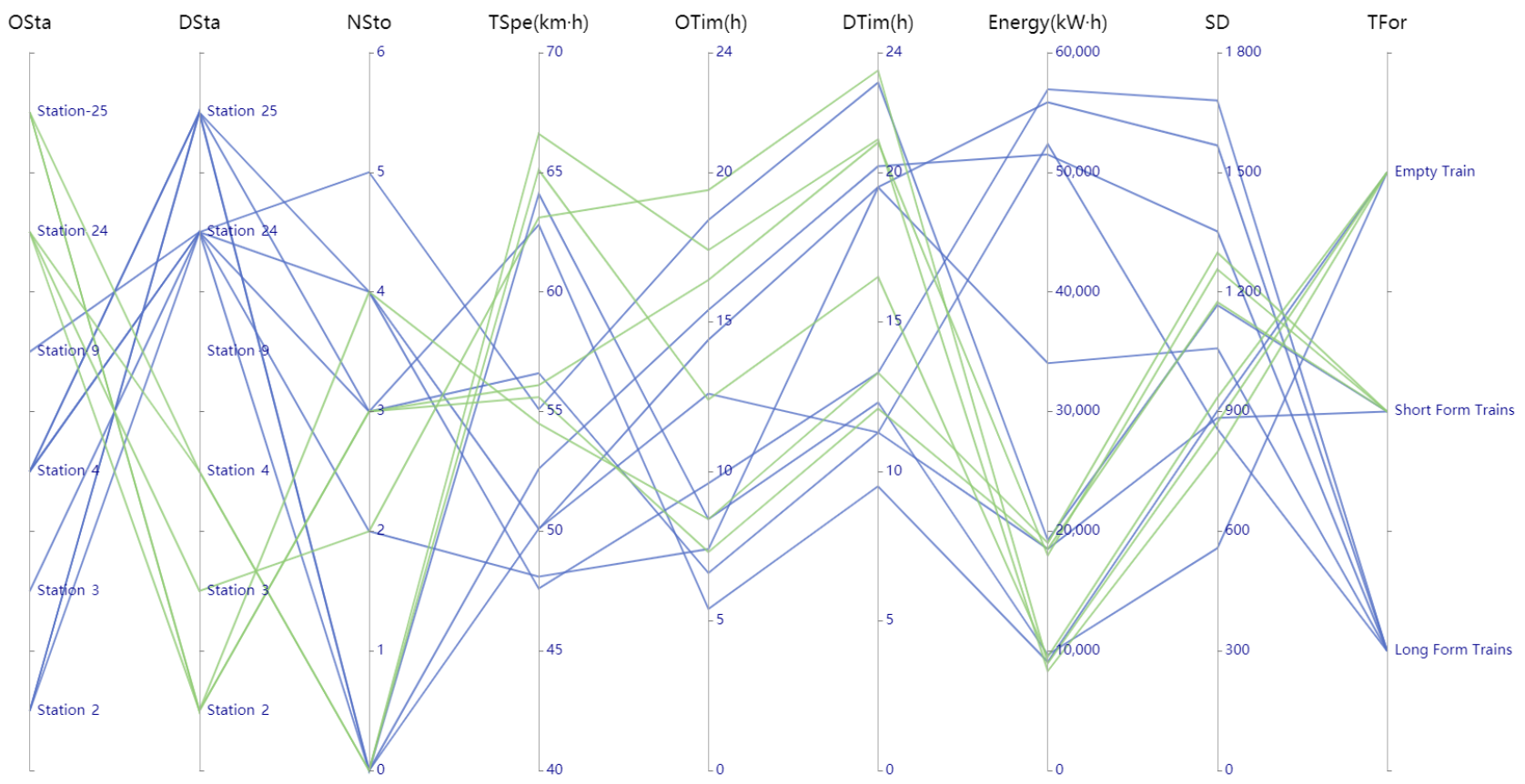

Figure 5. Energy consumption distribution patterns of the upper and lower trains in seven dimensions.

Among them, OSta is the origin station, DSta is the destination station, NSta is the number of stops, and TSpe is the train travel speed. OTim is the departure time, DTim is the arrival time, TFor is the train combination form, Energy is the mean energy consumption, and $\mathrm{SD}$ is the standard deviation of energy consumption.

In order to clarify the relationship between dimension and energy consumption, we compared the average energy consumption of long and short trains, and analyzed the effect of departure interval on energy consumption of long-form trains.

\subsection{Comparison of Average Energy Consumption of Long-and Short-Form Trains}

In this section, the energy consumption of long-form trains and short-form trains with the same transportation capacity was measured in different characteristic intervals (long distance, short distance, large slope, small slope, etc.), and the results are shown in Figure 6 and Table 6. 


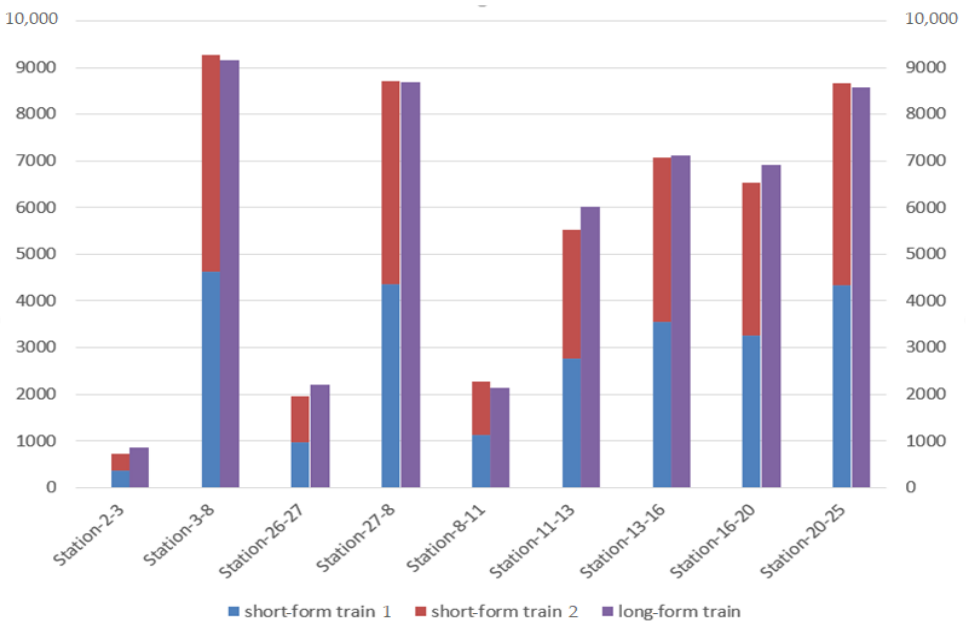

Figure 6. Example of comparison between the capacity of a long-form train (100 units) and two short-form trains (50 units).

Table 6. Comparison of energy consumption between a long-form train (100 units) and two shortform trains (50 units).

\begin{tabular}{ccccc}
\hline Section & $\begin{array}{c}\text { Short-Form } \\
\text { Train 1 }\end{array}$ & $\begin{array}{c}\text { Short-Form } \\
\text { Train 2 }\end{array}$ & $\begin{array}{c}\text { Long-Form } \\
\text { Train }\end{array}$ & Proportion \\
\hline Station 2-Station 3 & 367.6 & 367.6 & 860 & $-14.51 \%$ \\
Station 3-Station 8 & 4633.63 & 4633.63 & 9150 & $1.28 \%$ \\
Station 26-Station 27 & 978.52 & 978.52 & 2201 & $-11.08 \%$ \\
Station 27-Station 8 & 4359.05 & 4359.05 & 8690 & $0.32 \%$ \\
Station 8-Station 11 & 1134.04 & 1134.04 & 2145 & $5.74 \%$ \\
Station 11-Station 13 & 2759.94 & 2759.94 & 6027.32 & $-8.42 \%$ \\
Station 13-Station 16 & 3539.78 & 3539.78 & 7120 & $-0.57 \%$ \\
Station 16-Station 20 & 3265.2 & 3265.2 & 6912 & $-5.52 \%$ \\
Station 20-Station 25 & 4333.01 & 4333.01 & 8573 & $1.09 \%$ \\
\hline
\end{tabular}

When in the short distance interval (e.g., Station 2-Station 3, Station 26-Station 27), the energy consumption of long-form trains was greater than that of short-form train with the same transportation volume; when in the large gradient interval (e.g., Station 16-Station 20, Station 11-Station 13), the energy consumption of long-form train was greater than that of short-form trains with the same transportation volume. For Station 26-Station 27, Station 16-Station 20 and Station 11-Station 13, the energy consumption of the long-form train was greater than that of the short-form train for the same transport volume; when in the long-distance interval (e.g., Station 3-Station 8, Station 20-Station 25), the energy consumption of the long-form train was greater than that of the short-form train. Similarly, the energy consumption of the long-form train was smaller than that of the short-form train in the case of small slope interval (e.g., Station 27-Station 8). Train energy consumption was smaller than that of the short-form train. The specific values can be seen in Table 6 .

In summary, the combination of short-form trains into a long-form train in the interval with small spacing or large gradient generates more energy consumption (about $5 \sim 14 \%$ ), although it can improve the traffic density and make full use of the passing capacity of the section; on the contrary, in the interval with large spacing or small gradient, the long-form train had certain advantages in energy consumption (about $1-5 \%$ can be saved).

\subsection{The Effect of Departure Interval on Energy Consumption of Long Trains}

In order to study the influence of the departure interval on energy consumption, the long-form train was selected as an example to calculate the average value of energy consumption under different departure intervals (as shown in Figure 7). When the departure 
interval was longer than $15 \mathrm{~min}$, the trains on the line had less influence on each other, and the energy consumption of trains did not show great changes. If the interval was compressed, the average energy consumption increased as more trains were carried on the section line. For example, if the long-form train interval was compressed from $13 \mathrm{~min}$ to $9 \mathrm{~min}$, the energy consumption increased by about $3.6 \%$. Therefore, reducing the departure interval between trains may increase energy consumption while increasing the density and passing capacity.

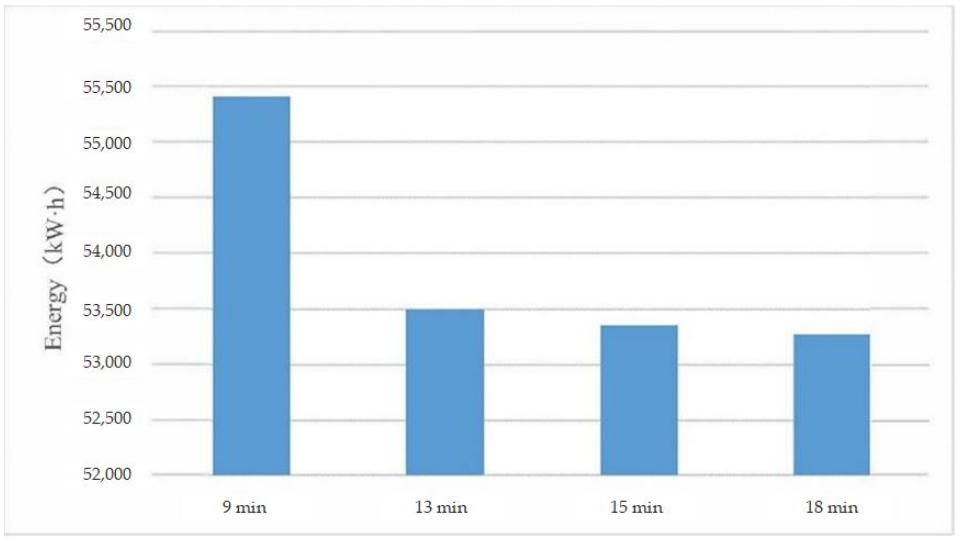

Figure 7. Distribution of energy consumption for long-form trains with different departure intervals.

In summary, the setting of departure interval and the planning of long- and short-form train grouping affect the energy consumption values. By comparing the experiments, the relationship between capacity utilization decision variables and energy consumption can be found as follows:

(1) Long-form trains generate more energy consumption when the departure interval is short or in a higher-gradient section. When the departure interval is short or in a higher-gradient section, combining short-form trains into a long-form train will generate more energy consumption (about $5-14 \%$ more), although it can improve the traffic density and passing capacity of the section; on the contrary, when the departure interval is long or in a lower-gradient section, a long-form train has a certain advantage in saving energy (about $1-5 \%$ ).

(2) Compressed departure intervals may cause an increase in energy consumption. For example, when compressing the departure interval of long-form trains, the energy consumption of a 9 min departure interval is higher by $3.6 \%$ compared to a $13 \mathrm{~min}$ departure interval.

\subsection{Analysis of Capacity and Energy Consumption}

The model solution results in Section 3 were influenced by the parameters $\lambda_{1}, \lambda_{2}$, and $\lambda_{3}$.

In this paper, we set up sensitivity analysis experiments to analyze the capacity and energy consumption in different scenarios by controlling parameters $\lambda_{1}, \lambda_{2}$, and $\lambda_{3}$ in Equation (30). The experimental results are shown in Figure 8. 


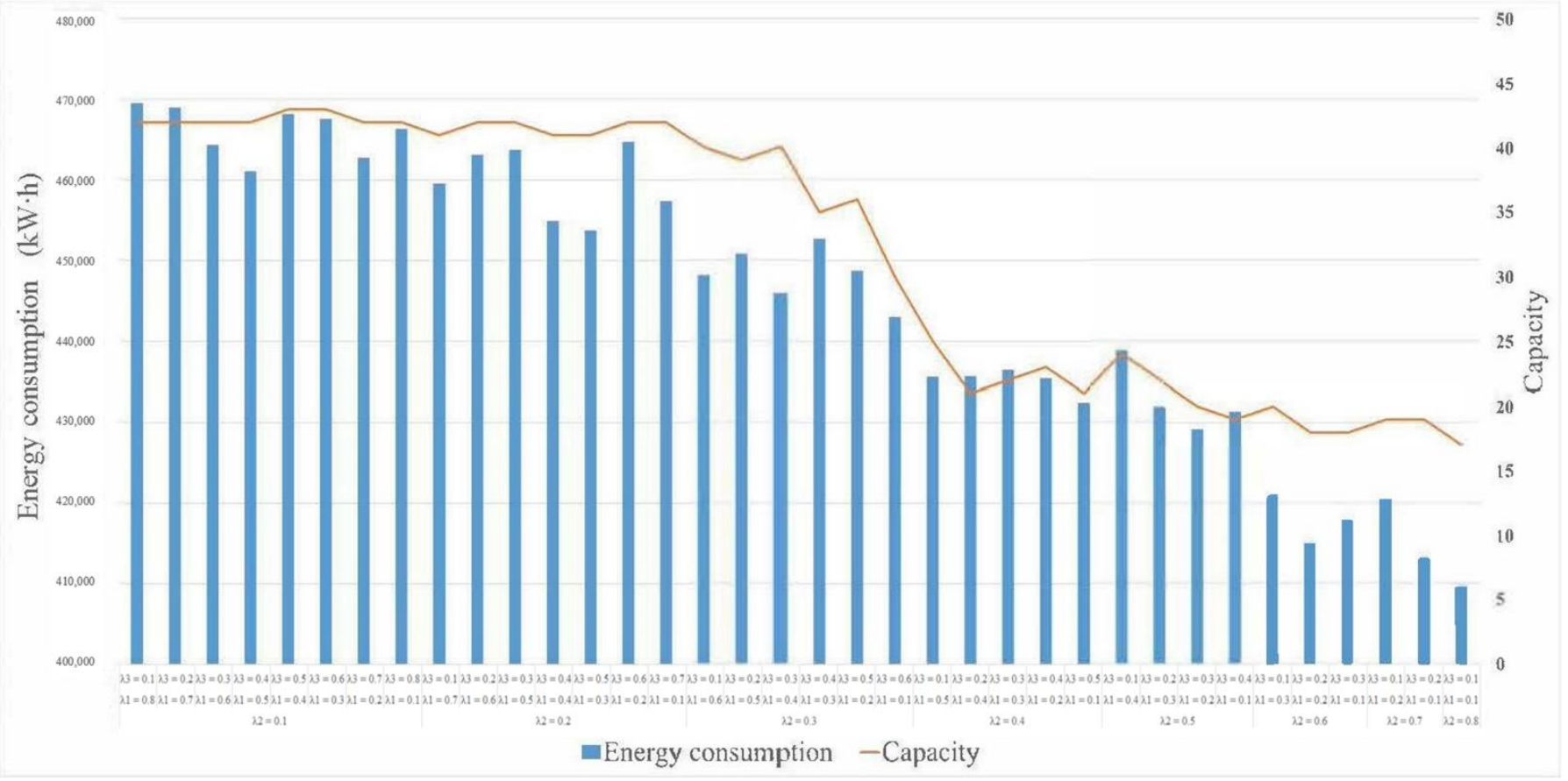

Figure 8. Experiment on capacity energy utilization analysis.

By constantly changing the value of $\lambda s$ in the objective function, it was found that as the energy consumption influence parameter $\lambda_{2}$ increased, the energy consumption of the plan decreased. The capacity value fluctuated and decreased when $\lambda_{2} \leq 0.3$, from the maximum capacity of 43 trains, but the decreasing range was small, and the fluctuation range was between 40 and 43 trains. What is more, with the continuous increase of $\lambda_{2}$, the capacity decreased precipitously, which was much larger than that of the previous scenario. When $\lambda_{2} \geq 0.5$, the capacity flattened out again.

It can be viewed that when $\lambda_{2} z \lambda_{1}=0.4 \lambda_{2}=0.3 \lambda_{3}=0.3$, at which time the capacity value was 40 trains. However, as energy consumption continued to decrease, the capacity declined rapidly when the energy provided could not support a large number of trains running. Finally, with the reduction in energy consumption, although the capacity remained reduced, it did not change much.

To sum up, for heavy-haul railway systems, energy consumption and capacity can be optimized simultaneously under a parameter set $\left(\lambda_{1}=0.4, \lambda_{2}=0.3\right.$, and $\left.\lambda_{3}=0.3\right)$. The different parameters of capacity and energy consumption have influence on the plan, and the recommended train plan varies with the $\lambda$ value. When the freight volume in the railway line does not reach the top capacity, the plans can be controlled to make the railway energy consumption level around $\lambda_{2}=0.3$. This way, the railway system can maintain a high level of capacity while minimizing the energy consumption.

\section{Conclusions}

In this paper, we studied railway coal transportation lanes. Based on the actual TTD data after the line operation and the longitudinal and cross-sectional information of the section where the trains are located, we used data analysis methods to find out the usage patterns of energy consumption, and use the mixed integer programming model to obtain a solution that can balance passing capacity and energy consumption. Specifically, it includes the following: (1) According to the kinematic model, train trajectory data (TTD) are used to depict energy consumption, including different tonnage ratings (tons, regular trains), different phases (acceleration, coasting, braking), and other cases. Through the assumption of Gaussian distribution, we analyzed its distribution pattern, obtained the relationship between energy consumption and the capacity, and obtained the specific 
energy consumption of multiple dimensions and high detail in different times and spaces, which could be used as the basis for the analysis of the objective function coefficients of the optimization model. (2) Based on time-space state network and the path analysis of train operation, a mixed integer programming model including energy consumption and capacity was established by comprehensively considering the constraints of section passing capacity, station loading and unloading capacity, and combined dismantling capacity. In addition, a branch-and-bound algorithm was designed to solve the model. (3) In this paper, we took a railway in northern China as an example to verify the method. (1) The mean value $\mu$ and standard deviation $\sigma$ of train energy consumption with different stopping schemes, tonnage ratings, and combination types of empty and loaded vehicles on the line section were calculated. (2) According to the influencing factors of train energy consumption, the relationship between capacity utilization and energy consumption was analyzed. (3) Transport organization plans with a balanced consideration of capacity and energy consumption were obtained. Among them, according to sensitivity analyses, we concluded that (1) shortening the departure interval from $13 \mathrm{~min}$ to 9 min generates more energy consumption, about 3.6\%; (2) combining short-form trains (50 units) into long-form trains (100 units) while increasing the traffic density and passing capacity also generates more energy consumption, about $5-14 \%$; and (3) by controlling weights of the optimization model, capacity-energy-balanced plans can be obtained with $\lambda_{1}=0.4$, $\lambda_{2}=0.3$, and $\lambda_{3}=0.3$.

In this paper, when constructing the railway organization optimization model, the influence of locomotive use, vehicle maintenance, and other factors on the train organization process was ignored, so further research can be conducted here. In the meantime, future research can further analyze railway field data comprehensively, so the energy consumption of trains operating in the station can be considered, and methods such as kinematic multi-mass models can be introduced to further improve the calculation of train energy consumption. Similarly, the traffic data used in the numerical experiments of this paper are of a specific period in a specific section, without considering the volatility of the traffic. The impacts of this capacity and energy consumption on train organization in extreme cases, i.e., periods of extreme capacity stress or extreme surplus, can be worth considering in future studies.

Author Contributions: Conceptualization, J.F.; methodology, J.F.; resources, J.F.; writing-original draft preparation, J.F.; writing-review and editing, J.F.; supervision, J.C.; validation, J.C. Both authors have read and agreed to the published version of the manuscript.

Funding: The research was supported by the National Natural Science Foundation of China (grant no. U1734204).

Institutional Review Board Statement: Not applicable.

Informed Consent Statement: Not applicable.

Data Availability Statement: Due to the nature of this research, the participants of this study did not agree for their data to be shared publicly.

Conflicts of Interest: The authors declare no conflict of interest.

\section{References}

1. Assad, A. Analytical models in rail transportation: An annotated bibliography. INFOR Inf. Syst. Oper. Res. 1981, 19, 59-80. [CrossRef]

2. Assad, A. Analysis of rail classification policies. INFOR Inf. Syst. Oper. Res. 1983, 21, 293-314. [CrossRef]

3. Bodin, L.D.; Golden, B.L.; Schuster, A.D.; Romig, W. A model for the blocking of trains. Transp. Res. Part B Methodol. 1980, 14, 115-120. [CrossRef]

4. Kim, N.S.; Van Wee, B. Assessment of co2 emissions for truck-only and rail-based intermodal freight systems in europe. Transp. Plan. Technol. 2009, 32, 313-333. [CrossRef]

5. Sieminski, A.; Energy Information Administration. International Energy Outlook 2016. Available online: https://www.csis.org/ events/eias-international-energy-outlook-2016 (accessed on 12 January 2021). 
6. Knörr, W.; Seum, S.; Schmied, M.; Kutzner, F.; Anthes, R. Ecological Transport Information Tool for Worldwide Transports-Methodology and Data Update; IFEU: Heidelberg, Germany; INFRAS: Bern, Switzerland; IVE: Hannover, Germany, 2011.

7. Jorgensen, M.W.; Sorenson, S.C. Estimating emissions from railway traffic. Int. J. Veh. Des. 1998, 20, 210-218. [CrossRef]

8. Kirschstein, T.; Meisel, F. Ghg-emission models for assessing the eco-friendliness of road and rail freight transports. Transp. Res. Part B Methodol. 2015, 73, 13-33. [CrossRef]

9. Zhou, X.; Tanvir, S.; Lei, H.; Taylor, J.; Liu, B.; Rouphail, N.M.; Frey, H.C. Integrating a simplified emission estimation model and mesoscopic dynamic traffic simulator to efficiently evaluate emission impacts of traffic management strategies. Transp. Res. Part D Transp. Environ. 2015, 37, 123-136. [CrossRef]

10. Lindgreen, E.; Sorenson, S.C. Simulation of Energy Consumption and Emissions from Rail Traffic; Technical University of Denmark, Department of Mechanical Engineering: Kongens Lyngby, Denmark, 2005; ISBN 87-7475-328-1.

11. Patterson, Z.; Ewing, G.O.; Haider, M. The potential for premium-intermodal services to reduce freight co2 emissions in the quebec city-windsor corridor. Transp. Res. Part D Transp. Environ. 2008, 13, 1-9. [CrossRef]

12. Howlett, P.G.; Pudney, P.J. Energy-Efficient Train Control; Springer Science \& Business Media: New York, NY, USA, 2012.

13. Lukaszewicz, P. Energy saving driving methods for freight trains. Wit Trans. Built Environ. 2004, 74. [CrossRef]

14. Cortés, C.E.; Vargas, L.S.; Corvalán, R.M. A simulation platform for computing energy consumption and emissions in transportation networks. Transp. Res. Part D Transp. Environ. 2008, 13, 413-427. [CrossRef]

15. Heinold, A.; Meisel, F. Emission rates of intermodal rail/road and road-only transportation in europe: A comprehensive simulation study. Transp. Res. Part D Transp. Environ. 2018, 65, 421-437. [CrossRef]

16. Wu, Q.; Spiryagin, M.; Cole, C. Train energy simulation with locomotive adhesion model. Railw. Eng. Sci. 2020, 1-10. [CrossRef]

17. Drish, W.F., Jr. Train Energy Model-User's Manual, Version 1.5; Railway Simulators; The National Academies of Sciences, Engineering, and Medicine: Washington, DC, USA, 1989.

18. Ritzinger, U.; Puchinger, J.; Hartl, R.F. Dynamic programming based metaheuristics for the dial-a-ride problem. Ann. Oper. Res. 2016, 236, 341-358. [CrossRef]

19. Cucala, A.P.; Fernandez, A.; Sicre, C.; Dominguez, M. Fuzzy optimal schedule of high speed train operation to minimize energy consumption with uncertain delays and driver's behavioral response. Eng. Appl. Artif. Intell. 2012, 25, 1548-1557. [CrossRef]

20. Domínguez, M.; Fernández-Cardador, A.; Cucala, A.P.; Gonsalves, T.; Fernández, A. Multi objective particle swarm optimization algorithm for the design of efficient ato speed profiles in metro lines. Eng. Appl. Artif. Intell. 2014, 29. [CrossRef]

21. Xiang, L.; Hong, K.L. Energy minimization in dynamic train scheduling and control for metro rail operations. Transp. Res. Part $B$ Methodol. 2014, 70, 269-284. [CrossRef]

22. Chen, D.; Li, S.; Li, J.; Ni, S.; Liu, X. Optimal high-speed railway timetable by stop schedule adjustment for energy-saving. J. Adv. Transp. 2019, 2019, 1-9. [CrossRef]

23. Zhang, H.; Jia, L.; Wang, L.; Xu, X. Energy consumption optimization of train operation for railway systems: Algorithm development and real-world case study. J. Clean. Prod. 2019, 214, 1024-1037. [CrossRef]

24. Yang, X.; Chen, A.; Ning, B.; Tang, T. A stochastic model for the integrated optimization on metro timetable and speed profile with uncertain train mass. Transp. Res. Part B Methodol. 2016, 91, 424-445. [CrossRef]

25. Bocharnikov, Y.V.; Tobias, A.M.; Roberts, C.; Hillmansen, S.; Goodman, C.J. Optimal driving strategy for traction energy saving on dc suburban railways. Iet Electr. Power Appl. 2007, 1, 675-682. [CrossRef]

26. Yun, B.; Baohua, M.; Fangming, Z.; Yong, D.; Chengbing, D. Energy-efficient driving strategy for freight trains based on power consumption analysis. J. Transp. Syst. Eng. Inf. Technol. 2009, 9, 43-50. [CrossRef]

27. Xiang, X.; Zhu, X. An optimization strategy for improving the economic performance of heavy-haul railway networks. J. Transp. Eng. 2016, 142, 04016001-04016003.04016013. [CrossRef]

28. Medanic, J.; Dorfman, M.J. Energy efficient strategies for scheduling trains on a line. IFAC Proc. Vol. 2002, 35, 481-486. [CrossRef]

29. Albrecht, T.; Oettich, S. A New Integrated Approach to Dynamic-Schedule Synchronization and Energy-Saving Train Control. In Computers in Railways VIII; WIT Press: Southampton, UK, 2002; Volume 61.

30. Ghoseiri, K.; Szidarovszky, F.; Asgharpour, M.J. A multi-objective train scheduling model and solution. Transp. Res. Part B Methodol. 2004, 38, 927-952. [CrossRef]

31. Sicre, C.; Cucala, P.; Fernández, A.; Jiménez, J.A.; Serrano, A.A. A Method to Optimise Train Energy Consumption Combining Manual Energy Efficient Driving and Scheduling. In Computers in Railways XII; WIT Press: Southampton, UK, 2010; Volume 114, pp. 549-560. [CrossRef]

32. Lancien, D.; Fontaine, M. Computing train schedules to save energy: The mareco program. Rev. Gén. Chem. Fer 1981, 100, 679-692. 